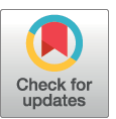

pISSN 2287-2728

eISSN 2287-285X

Review

\title{
Current understanding of primary biliary cholangitis
}

\author{
Atsushi Tanaka \\ Department of Medicine, Teikyo University School of Medicine, Tokyo, Japan
}

Primary biliary cholangitis (PBC) causes chronic and persistent cholestasis in the liver, eventually resulting in cirrhosis and hepatic failure without appropriate treatment. PBC mainly develops in middle-aged women, but it is also common in young women and men. PBC is considered a model of autoimmune disease because of the presence of diseasespecific autoantibodies, that is, antimitochondrial antibodies (AMAs), intense infiltration of mononuclear cells into the bile ducts, and a high prevalence of autoimmune diseases such as comorbidities. Histologically, PBC is characterized by degeneration and necrosis of intrahepatic biliary epithelial cells surrounded by a dense infiltration of mononuclear cells, coined as chronic non-suppurative destructive cholangitis, which leads to destructive changes and the disappearance of small- or medium-sized bile ducts. Since 1990, early diagnosis with the detection of AMAs and introduction of ursodeoxycholic acid as first-line treatment has greatly altered the clinical course of PBC, and liver transplantation-free survival of patients with PBC is now comparable to that of the general population. (Clin Mol Hepatol 2021;27:1-21)

Keywords: Anti-mitochondrial antibody; Epidemiology; Bezafibrate

\section{INTRODUCTION}

Primary biliary cholangitis (PBC), formally named primary biliary cirrhosis until 2016, is a chronic cholestatic liver disease. The first patient presenting with symptoms resembling PBC was described in the literature in $1851 .{ }^{1}$ When the term "primary biliary cirrhosis" initially appeared in the title of an article published in 1949 by Dauphinee and Sinclair, ${ }^{2}$ most early descriptions of PBC involved patients at the cirrhotic stage, with jaundice, ascites, and variceal bleeding; therefore, the nomenclature "primary biliary cirrhosis" was correct at that time. However, the use of biochemical and immunological tests in clinical settings has enabled the diagnosis of

\footnotetext{
Abbreviations:

2-OADC, 2-oxo-acid dehydrogenase complex; ALP, alkaline phosphatase; AMA, anti-mitochondrial antibody; APASL, Asian Pacific Association for the Study of the Liver; BCOADC-E2, branched chain 2-oxoacid dehydrogenase complex E2 subunit; BECs, biliary epithelial cells; CA, cholangitis activity; Cl, confidence interval; CNSDC, chronic non-suppurative destructive cholangitis; E. coli, Escherichia coli; E3BP, dihydrolipoamide dehydrogenase-binding protein; ELISA, enzyme-linked immunosorbent assay; FDA, Food and Drug Administration; FXR, farnesoid X receptor; GWAS, genome-wide association study; HA, hepatitis activity; HBV, hepatitis B virus; HCC, hepatocellular carcinoma; HLA, human leukocyte antigen; IBAT, ileal bile acid transporter; IFN, interferon; IL, interleukin; LPA, lysophosphatidic acid; LT, liver transplantation; MHC, major histocompatibility complex; OCA, obeticholic acid; OGDC-E2, 2-oxo-glutamic acid dehydrogenase complex E2 subunit; PBC, primary biliary cholangitis; PDC-E2, pyruvate dehydrogenase complex E2 subunit; RANKL, receptor activator of nuclear factor-kappaB ligand; RRs, risk ratios; UDCA, ursodeoxycholic acid; ULN, upper limit of normal
}

\section{Corresponding author: Atsushi Tanaka}

Department of Medicine, Teikyo University School of Medicine, 2-11-1, Kaga, Itabashi-ku, Tokyo 173-8605, Japan

Tel : +81-3-3964-1211, Fax: +81-3-3964-6627

E-mail: a-tanaka@med.teikyo-u.ac.jp

https://orcid.org/0000-0002-6358-5283 


\section{CLINICAL and MOLECULAR}

Volume_27 Number_1 January 2021

PBC at earlier stages. Furthermore, the establishment of ursodeoxycholic acid (UDCA) as a first-line treatment drug remarkably reduced disease progression to cirrhosis. In fact, while half of patients diagnosed as PBC had one or more symptoms at diagnosis in the 1980's, $75-80 \%$ of patients were asymptomatic without any complaint of symptom at diagnosis after 2000 in Japan. The serious gap between the disease manifestation and its misnomer became wider, and the term "cirrhosis" became not merely an inaccuracy but an active stigma for patients, motivated by the change of nomenclature of the disease, from cirrhosis to cholangitis. $^{3-10}$ The Asian Pacific Association for the Study of Liver (APASL) also officially approved this decision, and the new nomenclature "primary biliary cholangitis" is currently used in the official journal of the APASL."

\section{EPIDEMIOLOGY}

The prevalence and incidence of PBC vary considerably worldwide (Fig. 1). This discrepancy can be attributed to the true epidemiological difference between regions or study periods, to the variation in study designs for case finding or ascertainment, or difference in the diagnosis of PBC among physicians. Notably, awareness of PBC may still not be satisfactory in some Asian and African countries where epidemiological studies are scarce, and the sample size in some studies is very small. PBC is believed to
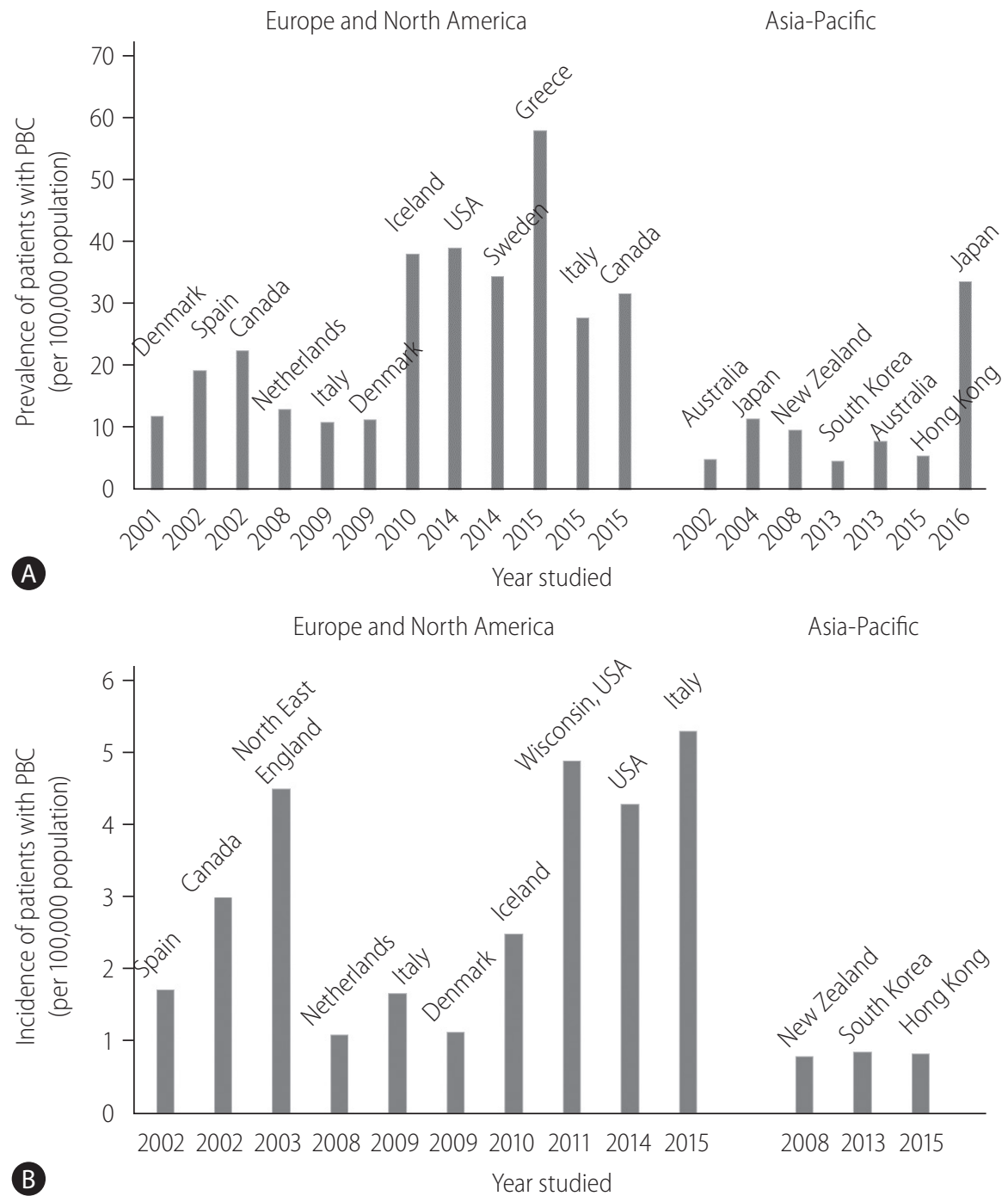

Figure 1. Epidemiological data of PBC over time and in different geographical regions. (A) The prevalence (per 100,000 population) and (B) incidence (per 100,000 population) of PBC. PBC, primary biliary cholangitis. 
be a rare disease in the Asia-Pacific region, and both the prevalence and incidence seemed to be lower in the Asia-Pacific region, as indicated by recent epidemiological studies in South Korea or Hong Kong (Fig. 1). 12,13 In contrast, a 2016 study in Japan reported that the point prevalence of PBC was 33.8 per 100,000 in the Japanese population, ${ }^{14}$ which was comparable to that in European countries, the United States, and Canada. A recent review from South Korea defined a "rare disease" by either the prevalence $(1,500-2,500$ per 100,000 population) or patient number $(<20,000) .{ }^{15}$ According to this definition, PBC is a rare disease, but interestingly, there is a substantial difference in the prevalence between Japan and South Korea or Hong Kong.

Other studies also indicated an increasing trend in the prevalence of PBC over time (Fig. 1A). ${ }^{16}$ Longitudinal studies in identical regions consistently showed an increase in the prevalence of PBC. ${ }^{14,17,18}$ Since sequential studies demonstrated an increasing incidence of PBC (1.67 in 2009 and 5.31 in 2015, in Italy $\left.{ }^{19,20}\right)$ or a relatively stable incidence $\left(2.6\right.$ in Sweden $\left.{ }^{18}\right)$, it is unclear whether a true increase or improved overall survival has contributed to the increasing prevalence of $\mathrm{PBC}$.

One of the signatures of PBC is its female preponderance. Retrospective analysis indicated that the female:male ratio was $9: 1^{21,22}$ in the 1990s and early 2000s, and this overt female predisposition has provided researchers a clue in clarifying the etiology of PBC. Notably, female predominance is still clearly observed today; however, it is less pronounced; the female:male ratio was less than 5:1 in most recent epidemiological studies and even 2.1:1. ${ }^{19}$ The reason for the relative increase in the number of male patients with PBC remains unclear, but a better recognition and a true increase in the incidence of $\mathrm{PBC}$ are likely responsible.

\section{ETIOLOGY}

\section{Tolerance breakdown against autoantigens}

PBC is a multifactorial and enigmatic disease; it remains unknown how and why PBC develops. Autoimmune attack targeted at biliary epithelial cells (BECs) through tolerance breakdown triggers disease onset.

The hallmark of PBC is anti-mitochondrial antibody (AMA), which are detected in $90-95 \%$ of patients with $\mathrm{PBC}_{1}{ }^{23,24}$ and the most disease-specific autoantibodies in human immunopathology. The high specificity of AMAs for PBC suggests that AMAs are not simple serological markers for diagnosis but are important in the immunopathology of PBC. AMAs recognize a family of enzymes located in the inner membrane of the mitochondria, named the 2-oxo-acid dehydrogenase complex (2-OADC), which mainly includes the pyruvate dehydrogenase complex E2 subunit (PDC-E2), the branched-chain 2-OADC E2 subunit (BCOADC-E2), the 2-oxoglutaric acid dehydrogenase complex E2 subunit (OGDC-E2), and dihydrolipoamide dehydrogenase-binding protein (E3BP). ${ }^{25}$ AMAs and autoreactive $\mathrm{CD}^{+}{ }^{+}$and $\mathrm{CD} 8^{+} \mathrm{T}$ cell epitopes are confined within a shared peptide sequence of the inner lipoyl domain of human PDC-E2. ${ }^{26}$

BECs and hepatocytes of patients with PBC express large amounts of human leukocyte antigen (HLA) classes I and II molecules. $^{27,28}$ In patients with PBC, BECs acts as nonprofessional antigen-presenting cells, and the interplay of BECs and T cells may, to some extent, account for bile duct loss. Indeed, BECs expresses adhesion molecules, cytokines, and chemokines, and recruit mononuclear cells in the biliary tract of the liver. One example is fractalkine (CX3CL1), a chemokine with both chemoattractant and cell-adhesive functions. ${ }^{29} \mathrm{~T}$ helper type 1-cytokine predominance and lipopolysaccharide in the microenvironment of injured bile ducts induce the upregulation of fractalkine expression in $B E C s$, followed by the chemoattraction of mononuclear cells expressing its receptor (CX3CR1), including $C D 4^{+}$and $C D 8^{+} T$ cells. ${ }^{30,31}$ Serum fractalkine levels in $\mathrm{PBC}$ are high in patients with marked cholangitis activity (CA) at early stages, and they decrease in response to treatment. ${ }^{32}$

PDC-E2 is a ubiquitous protein located in nearly all nucleated cells in the human body, and it remains unclear why autoreactive $T$ cells specific for PDC-E2 elicit cytotoxicity only against BECs in the liver. In this regard, it should be noted that PBC recurs even after liver transplantation (LT), indicating that the immunopathological susceptibility of BECs in PBC is not major histocompatibility complex (MHC)-specific but a general feature shared with autologous $\mathrm{BEC}$. The hypothesis to solve this enigma is that human intrahepatic BECs could maintain PDC-E2 immunologically intact within apoptotic blebs (apotopes) during apoptosis. ${ }^{33}$ Interestingly, a unique triad consisting of BEC apotopes, macrophages from patients with PBC, and AMAs could lead to rigorous production of inflammatory cytokine production. ${ }^{34}$

\section{Genetic predisposition}

Accumulating evidence also suggests that a combination of genetic predisposition and environmental triggering factors plays a crucial role in tolerance breakdown. 


\section{CLINCAL and MOLECULAR}

Volume_27 Number_1 January 2021

Table 1. Major gene loci associated with susceptibility of PBC, and other autoimmune diseases*

\begin{tabular}{|c|c|c|c|c|c|c|c|}
\hline Chromosome No. & Gene loci & $\begin{array}{c}\text { PBC (Europe/North } \\
\text { America) }\end{array}$ & PBC (Japan/China) & RA & IBD & MS & SLE \\
\hline 1 & CD58 & & Yes & $\checkmark$ & & $\checkmark$ & \\
\hline 1 & MMEL1, TNFRSF14 & Yes & & $\checkmark$ & $\checkmark$ & $\checkmark$ & \\
\hline 1 & IL12RB2 & Yes & & & & & \\
\hline 1 & DENND1B & Yes & & & $\checkmark$ & & \\
\hline 2 & IL1RL2/IL1RL1 & Yes & & & $\checkmark$ & & \\
\hline 2 & STAT4 & Yes & Yes & $\checkmark$ & & & $\checkmark$ \\
\hline 2 & CD28/CTLA4/ICOS & & Yes & $\checkmark$ & & $\checkmark$ & \\
\hline 2 & CCL20 (LARC) & Yes & & & $\checkmark$ & & \\
\hline 2 & BCL2L11 & & & & & & \\
\hline 2 & GPR35 & & & & $\checkmark$ & & \\
\hline 3 & PLCL2 & Yes & & & & $\checkmark$ & \\
\hline 3 & CD80 & Yes & Yes & & & $\checkmark$ & \\
\hline 3 & IL12A, SCHIP1 & Yes & Yes & & & $\checkmark$ & \\
\hline 3 & FOXP1 & & & & & & \\
\hline 3 & MST1 & & & & $\checkmark$ & & \\
\hline 4 & DGKQ & Yes & & & $\checkmark$ & $\checkmark$ & \\
\hline 4 & $N F-k B 1$ & Yes & Yes & & $\checkmark$ & & \\
\hline 4 & IL21 & & Yes & & $\checkmark$ & & \\
\hline 5 & IL7R & Yes & Yes & & $\checkmark$ & $\checkmark$ & \\
\hline 5 & PAM/C5orf30 & Yes & & $\checkmark$ & & & \\
\hline 5 & LOC285626/IL12B & Yes & & . & $\checkmark$ & $\checkmark$ & \\
\hline 6 & TNFAIP3 & Yes & & $\checkmark$ & $\checkmark$ & $\checkmark$ & $\checkmark$ \\
\hline 6 & $\mathrm{BACH} 2$ & & & & $\checkmark$ & & \\
\hline 7 & ELMO1 & Yes & & & $\checkmark$ & $\checkmark$ & $\checkmark$ \\
\hline 7 & IRF5 & Yes & & $\checkmark$ & $\checkmark$ & 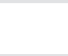 & $\checkmark$ \\
\hline 9 & TNFSF15 & & Yes & & $\checkmark$ & & \\
\hline 10 & IL2RA & & & $\checkmark$ & $\checkmark$ & $\checkmark$ & \\
\hline 11 & RPS6KA4 & Yes & & & $\checkmark$ & $\checkmark$ & \\
\hline 11 & CXCR5 & Yes & Yes & & & $\checkmark$ & $\checkmark$ \\
\hline 11 & POU2AF1 & & Yes & & & & \\
\hline 11 & CCDC88B & Yes & & & $\checkmark$ & & \\
\hline 11 & SIK2 & & & & & & \\
\hline 12 & TNFRSF1A & Yes & Yes & & & $\checkmark$ & \\
\hline 12 & $\mathrm{SH} 2 \mathrm{~B} 3$ & Yes & & $\checkmark$ & & & \\
\hline 12 & $\mathrm{HDAC7}$ & & & & $\checkmark$ & & \\
\hline 12 & RFX4, RIC8B & & & & & & \\
\hline 13 & TNFSF11 (RANKL) & Yes & & & $\checkmark$ & & \\
\hline 14 & RAD51L1 & Yes & & & & & \\
\hline 14 & TNFAIP2 & Yes & & & & & \\
\hline 15 & IL16 & & Yes & & & & \\
\hline
\end{tabular}


Table 1. Continued

\begin{tabular}{|c|c|c|c|c|c|c|c|}
\hline Chromosome No. & Gene loci & $\begin{array}{l}\text { PBC (Europe/North } \\
\text { America) }\end{array}$ & PBC (Japan/China) & $\mathrm{RA}$ & IBD & MS & SLE \\
\hline 16 & IL21R & & Yes & & & & \\
\hline 16 & PRKCB & & Yes & & & & $\checkmark$ \\
\hline 16 & CLEC16A, SOCS1 & Yes & & & $\checkmark$ & $\checkmark$ & $\checkmark$ \\
\hline 16 & CSNK2A2, CCDC113 & & Yes & & & & \\
\hline 16 & IRF8 & Yes & & $\checkmark$ & $\checkmark$ & $\checkmark$ & \\
\hline 17 & IKZF3-ORMDL3 & Yes & Yes & $\checkmark$ & $\checkmark$ & & \\
\hline 17 & MAPT, CRHR1 & Yes & & & & & \\
\hline 18 & TYK2 & Yes & & $\checkmark$ & $\checkmark$ & $\checkmark$ & \\
\hline 18 & ARID3A & & Yes & & & & \\
\hline 18 & SPIB & Yes & & & & & \\
\hline 18 & TCF4 & & & & & & \\
\hline 18 & CD226 & & & $\checkmark$ & $\checkmark$ & & \\
\hline 19 & PRKD2, STRN4 & & & & & & \\
\hline 21 & PSMG1 & & & & $\checkmark$ & & \\
\hline 21 & UBASH3A & & & $\checkmark$ & & & \\
\hline 22 & MAP3K7IP1/RPI3, SYNGR1 & Yes & Yes & & $\checkmark$ & & \\
\hline
\end{tabular}

PBC, primary biliary cholangitis; RA, rheumatoid arthritis; IBD, inflammatory bowel disease; MS, multiple sclerosis; SLE, systemic lupus erythematosus; IL, interleukin; RANKL, receptor activator of nuclear factor-kappaB ligand.

*Summary from eight genome-wide association study (GWAS)/iCHIP analyses from European countries and North America ${ }^{37-41,43-45}$ and three GWAS analyses from Japan and China ${ }^{42,46,47}$ in PBC, and eight GWAS analyses from European countries and North America. ${ }^{163-170}$

Genetic predisposition is believed to be a major contributing factor in the development of PBC. ${ }^{35}$

A recent study in Iceland, which took advantage of the unique local genealogical database, demonstrated that the familial risk of PBC was present not only in first-degree relatives but also in second- and third-degree relatives of patients with $\mathrm{PBC}$, with increased relative risk ratios (RRs) of 9.13 (95\% confidence interval $[\mathrm{Cl}], 4.17-16.76), 3.61$ (1.48-8.92), and 2.59 (1.35-4.67), respectively. ${ }^{36}$ Furthermore, the increased risk of PBC tended toward significance even in fourth- and fifth-degree relatives with RRs of $1.66(1.00-3.02)$ and $1.42(0.99-2.20)$, respectively. These findings clearly emphasize the importance of genetic risk in the pathogenesis of PBC.

Recent genome-wide association study (GWAS) analyses from North America, European countries, Japan, and China identified other HLA alleles that are strongly associated with susceptibility to $\mathrm{PBC}$ and revealed more than 40 non-HLA alleles contributing to PBC susceptibility (Table 1). ${ }^{37-48}$ Although risk alleles differ among studies and populations, they primarily belong to genes and pathways involved in antigen presentation and production of interleukin (IL)-12 (IRF5, SOCS1, TNFAIP3, NF-B, and IL-12A), activation of $T$ cells, and interferon (IFN)- $\gamma$ production (TNFSF15, IL12R, TYK2, STAT4, SOCS1, NF-KB, and TNFAIP3) as well as activation of $B$ cells and production of immunoglobulins (POU2AF1, SPIB, PRKCB, IKZF3, and ARID3A). These immune pathways could be important in the pathogenesis of $P B C$.

\section{Environmental triggers}

As environmental triggers, large-scale case-control studies have consistently found an association between urinary tract infections and cigarette smoking with $\mathrm{PBC}{ }^{49-52}$ Bacterial infection may have an impact on the etiology of PBC because PDC-E2 has a molecular mimic between human PDC-E2 and Escherichia coli (E. coli) PDC-E2, and thus, E. coli infection may trigger the breaking of immunological tolerance against human PDC-E2. Case-control studies also illustrate that xenobiotic modification of PDC-E2 with chemicals abundantly found in daily life, such as lipsticks, hair dyes, and nail polish, has a role in generating immunogenic neoantigens and breaking tolerance in PBC..$^{51,53-57}$ Finally, dysbiosis of 
the gut microbiota was found in patients with PBC, and interestingly, it was partially resolved with UDCA treatment. ${ }^{58}$

\section{Microbiota and bile acids}

Early environmental exposures can influence microbiome development. Evidence for the role of the microbiome in the etiology of PBC includes the effect of diet and the higher prevalence of PBC in Western nations in the Northern hemisphere. ${ }^{59}$ Diet is the primary external factor that can affect the microbiome, and changes in the microbiome can be affected by bile acids. ${ }^{60} \mathrm{It}$ is known that not all commensal bacteria are equally susceptible to bile acids, ${ }^{61}$ with $E$. coli and Helicobacter spp. being particularly resistant. Bile acids act as signaling molecules involved in glucose-lipid metabolism. The main bile acids in humans include cholic and chenodoxycholic acids and are synthesized in the liver. ${ }^{62}$ Bile acids have several other effects that maintain healthy liver tissue, including the regulation of glucose tolerance and insulin sensitivity. Bile acids are also known to induce sterol regulatory element-binding protein-1c production, which regulates the biosynthesis of cholester$\mathrm{ol}$, and also regulates the expression of lipogenesis genes such as glycerol-3-phosphate acyltransferase, acetyl-CoA carboxylase, and fatty acid synthase, thus offering protection against hyperlipidemia. ${ }^{63}$ Besides their effects on liver homeostasis, bile acids may alter the microbiome and hepatic regeneration, and thereby play a role in the pathogenesis of $\mathrm{PBC}{ }^{64}$ The chronic cholestasis seen in $\mathrm{PBC}$ that results from the microbiota affected by bile acids in turn can lead to aberrant expression of bile acid transporters and nuclear receptors, which can in turn cause liver damage, leading to a vicious cycle for chronic liver damage with bile acids as the pivotal determinant. ${ }^{65}$ It is clear that the role of bile acids and bile salts in the pathogenesis of PBC is extremely complicated, and is influenced by a number of interacting mechanisms.

Studies on changing the microbiome to be more consistent with healthy controls can be achieved through the use of UDCA treatment, but the effects of generating a healthier "microbiome" on the development of autoimmune liver disease are still unclear. It is known that a healthy microbiome tends to be beneficial for products such as single chain fatty acids ${ }^{66}$ and less proinflammatory cytokines such as TNFa and IFNY. ${ }^{67}$

\section{DIAGNOSIS}

A diagnosis of PBC is made when 2 or 3 following items are met: the 1) consistent elevation of cholestatic enzymes, 2) detection of AMA, and 3) typical liver histology. ${ }^{58,68,69}$ Figure 2 shows a diagnostic flowchart. Because of the very high sensitivity and

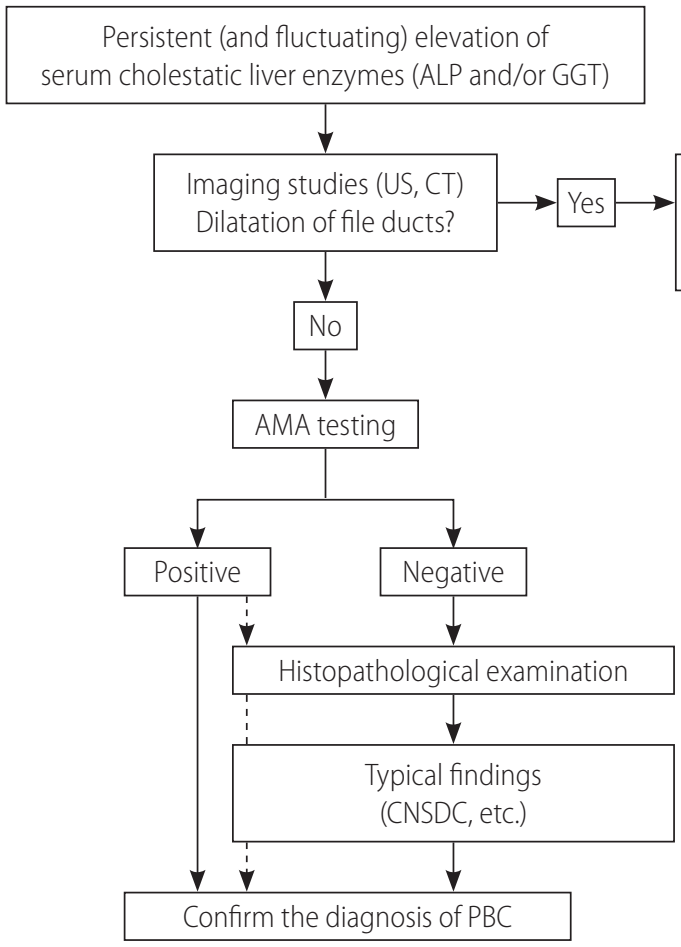

Explore other etiologies (malignant tumors, PSC, gallstones)
Figure 2. A diagnostic flowchart of patients with PBC. ALP, alkaline phosphatase; GGT, gamma glutamyl transferase; US, ultrasonography; CT, computed tomography; PSC, primary sclerosing cholangitis; AMA, anti-mitochondrial antibody; CNSDC, chronic non-suppurative destructive cholangitis; PBC, primary biliary cholangitis. 
specificity of AMA in the diagnosis of PBC, detectable AMA and elevation of alkaline phosphatase (ALP) levels are adequate for the diagnosis of PBC, and liver biopsy is not mandatory in many cases. Nevertheless, since histopathological stage at baseline is an independent prognostic marker of survival, as demonstrated by a recent large-scale retrospective study, ${ }_{1}^{70}$ liver biopsy is recommended for predicting long-term outcome but is not necessary in making a diagnosis. A histological examination is required in atypical cases, including suspicious AMA-negative PBC and autoimmune hepatitis/PBC overlap.

In clinical settings, AMA is often determined by enzyme-linked immunosorbent assay (ELISA) or immunofluorescence. Traditionally, at least nine AMA subtypes have been identified, and four of them (M2, M4, M8, and M9) seemed to be associated with PBC. ${ }^{71}$ since anti-M2 antibody was directed to 2-OADC and the most specific antibody to PBC, the M2 subtype of AMA (AMA-M2) is currently used as AMA in daily clinical practice. In ELISA, a combination of three recombinant mitochondrial proteins (PDC-E2, BCOADC-E2, and OGDC-E2) was used as the antigen. The titer of AMAs is not associated with disease progression or the patient's clinical course. AMAs are occasionally detected in less than $1 \%$ of healthy individuals with normal liver test results. ${ }^{72,73}$ Individuals who are AMA-positive are at higher risk of developing PBC and require close follow-up, although the risk does not appear to be high, as previously believed. A large-scale cohort study in France demonstrated that the prevalence of AMA-positive patients without evidence of PBC was 16.1 per 100,000 population, and one in six patients with AMA positivity and a normal ALP level developed PBC within 5 years..$^{74}$ Conversely, a recent study from China demonstrated that more than $80 \%$ of patients with AMA without elevation of serum ALP levels also developed histological characteristics of PBC, suggesting the presence of undiagnosed PBC patients among those with normal ALP levels and AMA positivity. ${ }^{75}$ It remains unclear whether these individuals will progress to ad- vanced disease, as in typical PBC, and how they should be clinically treated.

Among several anti-nuclear antibodies, sp100 and gp210 are frequently found in the sera of patients with $\mathrm{PBC}$, and, thus, aid in diagnosing patients with probable PBC but undetectable AMA positivity. A combination of three mitochondrial antigens, sp100, and gp210, ("PBC screen") had a sensitivity of $83.8 \%$ and specificity of $94.7 \%$ for diagnosing PBC and was considered appropriate as the first-line screening test. ${ }^{76}$ Molecular mimicry between mitochondrial antigens and sp100/gp210 was reported. ${ }^{77}$ The detection of gp210 may be associated with progression of the disease in UDCA-treated patients, ${ }^{78}$ but this observation requires further validation.

Histopathologically, the pathology of PBC is exclusively located in the intrahepatic small- or middle-sized bile ducts. A dense infiltration of mononuclear cells around the intrahepatic small bile ducts (interlobular bile ducts), coined as chronic non-suppurative destructive cholangitis (CNSDC), and granuloma formation are characteristic findings. Eventually, intrahepatic small bile ducts disappear from the liver, and chronic cholestatic features gradually develop. Hepatitis activity (HA) and chronic CA contribute to progressive hepatocellular damage and fibrosis, resulting in liver cirrhosis and hepatic failure.

The Scheuer's ${ }^{79}$ or Ludwig et al.'s $s^{80}$ classifications has been used for a long time as the classification system in histological staging of PBC pathology. In Scheuer's classification, florid duct lesions (CNSDC), ductular proliferation, scarring, and nodular cirrhosis are representative findings of stages 1, 2, 3, and 4, respectively (Fig. 3). However, as described in the original report by Scheuer, there is considerable overlap of findings between these stages; CNSDC can be observed even in the liver with nodular cirrhosis. Additionally, the pathology of PBC is not always distributed evenly in the liver; hence, sampling error can occur when determining the stages with these systems.
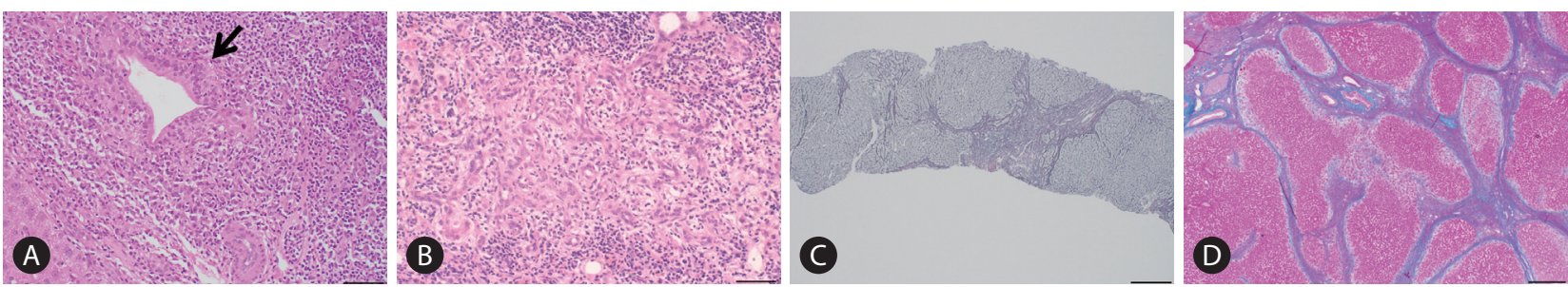

Figure 3. Histopathological findings in PBC characterizing stage 1, 2, 3, and 4 of the Scheruer's classification. (A) Chronic non-suppurative destructive cholangitis (arrow, hematoxylin, and eosin staining). Black bar indicates 400 mm. (B) Ductular proliferation (hematoxylin and eosin staining). Black bar, 400 mm. (C) Scarring (silver impregnation staining). Black bar, 100 mm. (D) Nodular cirrhosis (hematoxylin and eosin staining). Black bar, 200 mm. All these figures were kindly provided by Professor Kenichi Harada (Kanazawa University, Kanazawa, Japan). 


\section{CLINICAL and MOLECULAR}

In order to overcome these limitations, Nakanuma et al. proposed a new histological staging and grading system for PBC (Tables 2-4). ${ }^{81}$ In Nakanuma's classification, the scores for fibrosis, bile duct loss, and deposition of orcein-positive granules were used for staging, whereas CA and HA were used for grading. CA is determined by the presence of chronic cholangitis or CNSDC, and $\mathrm{HA}$ is defined by the presence of interface hepatitis or lobular hepatitis. Overall survival was stratified better with Nakanuma's classification than with the classic system. ${ }^{82}$

Table 2. Nakanuma's classification: staging of $P B C^{81}$

Stage 1 (no progression): score $0^{*}$

Stage 2 (mild progression): score 1-3

Stage 3 (moderate progression): score 4-6

Stage 4 (advanced progression): score 7-9

PBC, primary biliary cholangitis.

*The score for staging is the sum of the scores for fibrosis, bile duct loss, and deposition of orcein-positive granules, as shown below.

\section{TREATMENT}

\section{UDCA}

Since the first report demonstrating its efficacy for $\mathrm{PBC}{ }^{83}$ UDCA has dramatically altered the natural course of $P B C$ and has been approved as a first-line therapy for PBC worldwide. ${ }^{58,69,84}$ UDCA is used at a dose of $13-15 \mathrm{mg} / \mathrm{kg} / \mathrm{day}$, and is recommended for all patients with PBC with elevated liver biochemistry levels.

UDCA improves serum biochemical abnormalities, delays the histological progression and development of varices, and prolongs LT-free survival. Interestingly, a recent retrospective study on a large cohort demonstrated that the LT-free survival of UDCAtreated PBC patients was significantly improved compared to those that received no treatment and also in a population with incomplete biochemical response to UDCA. ${ }^{85}$

Approximately $20-30 \%$ of patients with PBC exhibited incomplete biochemical responses to UDCA. The outcomes of these patients were significantly worse than those with complete respons-

Table 3. Nakanuma's classification: scoring of $\mathrm{PBC}^{81}$

\begin{tabular}{llll}
\hline & \multicolumn{1}{c}{ Fibrosis } & \multicolumn{1}{c}{ Bile duct loss } & Deposition of orcein-positive granules \\
\hline Score 0 & No or limited portal fibrosis & No & No deposition \\
Score 1 & Portal fibrosis & Yes, in $<1 / 3$ of the portal tracts & $\begin{array}{c}\text { Deposition in several periportal hepatocytes in }<1 / 3 \\
\text { of the portal tracts }\end{array}$ \\
Score 2 & Bridging fibrosis & Yes, in $1 / 3-2 / 3$ of the portal tracts & $\begin{array}{c}\text { Deposition in variable periportal hepatocytes in } \\
1 / 3-2 / 3 \text { of the portal tracts }\end{array}$ \\
Score 3 & Cirrhosis & Yes, in $>2 / 3$ of the portal tracts & $\begin{array}{c}\text { Deposition in many periportal hepatocytes in }>2 / 3 \\
\text { of the portal tracts }\end{array}$ \\
\end{tabular}

Table 4. Nakanuma's classification: grading of necroinflammatory activities of $\mathrm{PBC}^{81}$

\begin{tabular}{|c|c|}
\hline & Cholangitis activity \\
\hline CA0 (no activity) & No cholangitis but mild duct epithelial damage may be present \\
\hline CA1 (mild activity) & 1 bile duct with evident chronic cholangitis \\
\hline CA2 (moderate activity) & $\geq 2$ bile ducts with evident chronic cholangitis \\
\hline \multirow[t]{2}{*}{ CA3 (marked activity) } & $\geq 1$ bile duct with CNSDC \\
\hline & Hepatitis activity \\
\hline HAO (no activity) & No interface hepatitis and no or minimal lobular hepatitis \\
\hline HA1 (mild activity) & $\begin{array}{l}\text { Interface hepatitis affecting } \geq 10 \text { continuous hepatocytes in } 1 \text { portal tract or fibrous septum, and mild-moderate } \\
\text { lobular hepatitis }\end{array}$ \\
\hline HA2 (moderate activity) & $\begin{array}{l}\text { Interface hepatitis affecting } \geq 10 \text { continuous hepatocytes in } \geq 2 \text { portal tracts or fibrous septa, and mild-moderate } \\
\text { lobular hepatitis }\end{array}$ \\
\hline HA3 (marked activity) & $\begin{array}{l}\text { Interface hepatitis affecting } \geq 20 \text { continuous hepatocytes in } \geq 1 / 2 \text { of the portal tracts, and moderate lobular } \\
\text { hepatitis or bridging or zonal necrosis }\end{array}$ \\
\hline
\end{tabular}

PBC, primary biliary cholangitis; CA, cholangitis activity; CNSDC, chronic non-suppurative destructive cholangitis; HA, hepatitis activity. 
es to UDCA. ${ }^{85}$ It is strongly recommended that patients with incomplete responses to UDCA commence second-line treatment in addition to UDCA. For this purpose, various criteria employing combinations of biochemical markers at 1 year after commencement of UDCA treatment have been proposed (Table 5). ${ }^{86-95}$ Therefore, the "UDCA response score," which predicts treatment response before starting UDCA treatment with baseline clinical variables, has been proposed. ${ }^{96}$ Very recently, the validity of the UDCA response score was demonstrated in a Japanere cohort. ${ }^{97}$

\section{Obeticholic acid (OCA)}

OCA is a selective ligand of the farnesoid $X$ receptor (FXR). In an international cohort, prospective, randomized, placebo-controlled trial (POISE trial), 217 patients with PBC who showed an incomplete response (serum ALP level >1.67xupper limit of normal [ULN]) or an abnormal total bilirubin level $(<2 \times U L N)$, or were intolerant to UDCA were enrolled and received 5-10 mg of OCA, 10 mg of OCA, and a placebo for 1 year. The primary end point was an ALP level $<1.67 \times U L N$ with $>15 \%$ reduction from the baseline and normal bilirubin levels. Among those patients, 46-47\% achieved the primary end point. ${ }^{98}$ Consequently, OCA received accelerated approval from the United States Food and Drug Administration (FDA) approval on May 27, 2016.
Although OCA has become the long-awaited second-line drug officially approved for PBC, it is still unsatisfactory for several reasons. First, the response rate to OCA was at most 50\%, which means that up to $50 \%$ of the patients did not respond to OCA. Second, pruritus, a symptom frequently experienced by patients with PBC, appeared as an adverse effect in $56-68 \%$ of those treated with OCA. Third, the appropriate treatment duration for OCA should be continued for patients refractory to UDCA; thus, OCA may be prescribed lifelong along with UDCA. Based on the high cost of OCA ( $\$ 69,350$ per year), its never-ending prescription places substantial economic burdens on patients and societies; thus, it is not cost-effective. ${ }^{99}$ Finally, it has not yet been confirmed whether the primary end points (ALP level $<1.67 \times U L N$ with $>15 \%$ reduction from the baseline and normal bilirubin level) are associated with improvement of long-term outcomes. Therefore, follow-up studies of the POISE trial are required by the FDA; a phase 3 study is currently ongoing (COBALT, NCT02308111), and the interim results at 3-year treatment suggested biochemical efficacy and safety ${ }^{100}$ as well as histological improvement ${ }^{101}$ of OCA. Regardless, the safety concerns of OCA should not be underestimated as the FDA released a warning in September 2017 stating that the use of OCA in PBC patients with decompensated cirrhosis (Child-Pugh-Turcotte class B and C) was associated with clinical worsening or even death.

Table 5. Criteria defining biochemical responses to UDCA

\begin{tabular}{|c|c|c|c|}
\hline Criteria & $\begin{array}{l}\text { Number of } \\
\text { patients }\end{array}$ & Duration & Definition \\
\hline \multicolumn{4}{|l|}{ Qualitative definition } \\
\hline Barcelona $^{95}$ & 192 & 1 year & Normal ALP level or reduction in the ALP level by $>40 \%$ \\
\hline Paris-1 $1^{88}$ & 292 & 1 year & ALP level $<3 \times U L N$, AST level <2xULN, normal bilirubin level \\
\hline Rotterdam 90 & 375 & 1 year & Normal bilirubin level, normal albumin level \\
\hline Toronto $^{91}$ & 69 & 2 year & ALP level $\leq 1.67 \times U L N$ \\
\hline Ehime $^{86}$ & 83 & 6 months & Normal GGT level or reduction in the GGT level by $\geq 70 \%$ \\
\hline Paris- $11^{89}$ & 165 & 1 year & ALP level $<1.5 \times U L N$, AST level $<1.5 \times U L N$, normal bilirubin level \\
\hline Rochester $^{94}$ & 73 & 1 year & ALP level $\leq 1.67 \times U L N$, bilirubin level $\leq 1$ mg/dL \\
\hline International (Global PBC) $)^{93}$ & 4,845 & 1 year & ALP level $<2 \times U L N$, normal bilirubin level \\
\hline \multicolumn{4}{|l|}{ Quantitative scores } \\
\hline GLOBE score ${ }^{92}$ & 4,119 & 1 year & $\begin{array}{l}\text { Bilirubin level, ALP level, albumin level, and platelet count at } 1 \text { year, age at } \\
\text { baseline }\end{array}$ \\
\hline UK-PBC score ${ }^{87}$ & 3,165 & 1 year & $\begin{array}{l}\text { ALP level, AST/ALT level, and bilirubin level at } 1 \text { year, albumin level and platelet } \\
\text { count at baseline }\end{array}$ \\
\hline
\end{tabular}

UDCA, ursodeoxycholic acid; ALP, alkaline phosphatase; ULN, upper limit of normal; AST, aspartate aminotransferase; ALT, alanine aminotransferase; GGT, gamma glutamyl transferase. 


\section{Fibrates}

Fibrates are peroxisome proliferator-activated receptor- $a$ and pregnane $\mathrm{X}$ receptor agonists and result in the reduction of $d e$ novo bile acid synthesis and upregulation of bile acid transporters. ${ }^{102}$ Fibrates (fenofibrate and bezafibrate) were originally indicated for dyslipidemia and are used to decrease serum cholesterol and triglycerides. Bezafibrate was first reported as biologically effective for patients with PBC who were refractory to UDCA in $1999 .^{103}$ A prospective, randomized, placebo-controlled study of bezafibrate in PBC patients with incomplete responses to UDCA from France demonstrated that an add-on of bezafibrate to UDCA for 2 years significantly improved liver biochemistry levels and liver stiffness. ${ }^{104}$ In another study, additional evidence from Japan showed that the observed LT-free survival of patients treated with combination therapy of UDCA and bezafibrate was significantly superior to the expected LT-free survival of those treated with UDCA monotherapy according to the GLOBE and UK-PBC scores. ${ }^{105}$ In Japan, bezafibrate has been used as a de facto second line treatment for patients who exhibited an incomplete response to UDCA. The proportion of patients treated with UDCA and bezafibrate and the LT-free survival stratified by the diagnosis year are shown in Figure 4. Until 1990, only $56 \%$ and $2 \%$ of patients were treated with UDCA and bezafibrate, respectively, and the LT-free 5 -year survival rate of patients with PBC was 59\%. By contrast, $91 \%$ and $16-17 \%$ of patients were treated with UDCA and bezafibrate after 2000, and the LT-free 5 -year survival rate was significanltly improved to $93-94 \%(P<0.001)$. Bezafibrate may also improve pruritus of $\mathrm{PBC}^{106} \mathrm{~A}$ prospective clinical trial on this topic is ongoing (FITCH trial, NCT02701166).

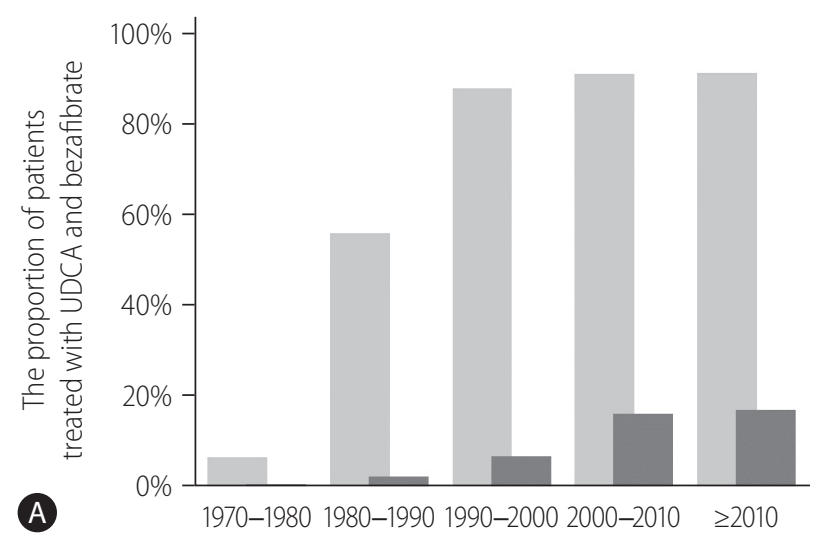

Fenofibrate was reported to decrease serum ALP levels in studies from Japan and China, ${ }^{107,108}$ whereas the adjunct use of fenofibrate with UDCA showed no association with decreased serum ALP levels in a United Kingdom study. ${ }^{109}$ Participants were recruited for a prospective randomized study in China (clinical trial ID: NCT02965911). However, these two prospective clinical trials showed notable improvements in liver enzyme levels at 12 or 24 months as the primary end point. Even after these trials were terminated, it is still unknown whether long-term outcomes are improved with additional treatment with fibrates, so follow-up studies of these trials are needed.

\section{LT}

Despite improvements in medical treatment for PBC, LT is the only treatment option for patients with decompensating events or intolerable pruritus. A recent study utilizing the European Liver Transplant Registry demonstrated a significant decrease in LT in PBC over the last 30 years after the introduction of UDCA in clinical settings. ${ }^{110}$ The proportion of $L T$ for PBC decreased from 20\% of all LT cases in 1986 to $4 \%$ in $2015(P<0.001)$. The absolute number of transplants was the highest in $1994(n=279)$, which decreased to an average of 200 in the last decade. This decrease is striking in contrast to the substantial increase in the prevalence of PBC at the same time. ${ }^{16}$

While the long-term outcome after $\mathrm{LT}$ for $\mathrm{PBC}$ is excellent overall, ${ }^{111-113}$ recurrence of $P B C$ after $L T$ is not uncommon. The reported incidence of recurrent PBC differs widely between $11 \%$ and $42 \%{ }^{114-129}$ Although several studies have reported risk factors associated with recurrence of $\mathrm{PBC}$, most consistently demonstrated

Figure 4. A change of treatment and outcome over time in Japan. (A) The proportion of patients treated with UDCA (light gray bars) and bezafibrate (dark gray bars) in Japan stratified by the diagnosis year. (B) The LT-free survival rate of patients with PBC in Japan, stratified by the diagnosis year. LT, liver transplantation; UDCA, ursodeoxycholic acid; PBC, primary biliary cholangitis. 
that the use of tacrolimus is associated with an increased risk of recurrence. ${ }^{115,116,123,126-128}$ For example, a recent study of 785 patients with PBC from North America and Europe who underwent LT between February 1983 and June 2016 indicated that tacrolimus was linked to the recurrence of PBC. Although the use of cyclosporine was protective, the 5-year probabilities of recurrence of PBC were reported to be $28 \%$ and $11 \%$ in patients receiving tacrolimus and cyclosporine, respectively $(P<0.001) .{ }^{125}$ On the other hand, the role of tacrolimus as an increasing agent of recurrent PBC does not seem to be the case in other ethnicities. Recently, two cohort studies from Japan demonstrated that the increased frequency of recurrent $\mathrm{PBC}$ is associated with initial treatment with cyclosporine after $\mathrm{LT}^{117,122}$

Although it is believed that recurrence of PBC does not have a significant impact on long-term outcomes, such as overall survival, ${ }^{123,130}$ a recent study of 785 PBC patients from 13 centers in North America and Europe who received LT with a median followup of 6.9 years (interquartile range, 6.1-7.9) reported opposite and unexpected results that disease recurrence was found in 240 patients (31\%). Importantly, graft and patient survival rates were significantly impaired in those with recurrent $\mathrm{PBC}(P=0.004$ and 0.001 , respectively). ${ }^{125}$ It is imperative to determine whether recurrent $\mathrm{PBC}$ has a clinically significant impact on patient and graft survival. Furthermore, since UDCA treatment seems to be effective in improving markers of cholestasis, it does not effectively reduce the frequency and risk of recurrence of PBC after $L T{ }^{130}$ Therefore, effective strategies to halt the recurrence of $\mathrm{PBC}$ are urgently needed.

\section{Treatment flowchart}

In Figure 5, a proposed treatment flowchart for patients with PBC is shown. UDCA treatment $(13-15 \mathrm{mg} / \mathrm{kg} /$ day) is recommended for all patients diagnosed with PBC, with elevated cholestatic liver enzymes. Treatment response should be judged at 1 year of UDCA treatment with the biochemical criteria shown in Table 5. Since most newly diagnosed PBC patients are at an early stage in daily clinical practice, the Paris II criteria designed for early stage patients may be suitable and easy to use. If the treatment response is complete, UDCA monotherapy should be continued and no additional treatment is required. In patients with incomplete response, add-on of the second-line treatment is definitely necessary; otherwise, the long-term outcome would deteriorate. The evidence-based choice of second-line medication is very difficult because no drug has been demonstrated to improve long-term outcomes. In Japan, a de facto use of bezafibrate as a second-line treatment appears to contribute to the improvement of long-term outcome, and it is expected to demonstrate in a large scale cohort a significant association of a combination of UDCA and bezafibrate with reduced mortality or need for LT.

Alternatively, response to UDCA can be predicted before commencement of UDCA therapy using the UDCA Response Score, and initiation of treatment with a combination of UDCA and bezafibrate would be a choice in cases with prediction of poor response.

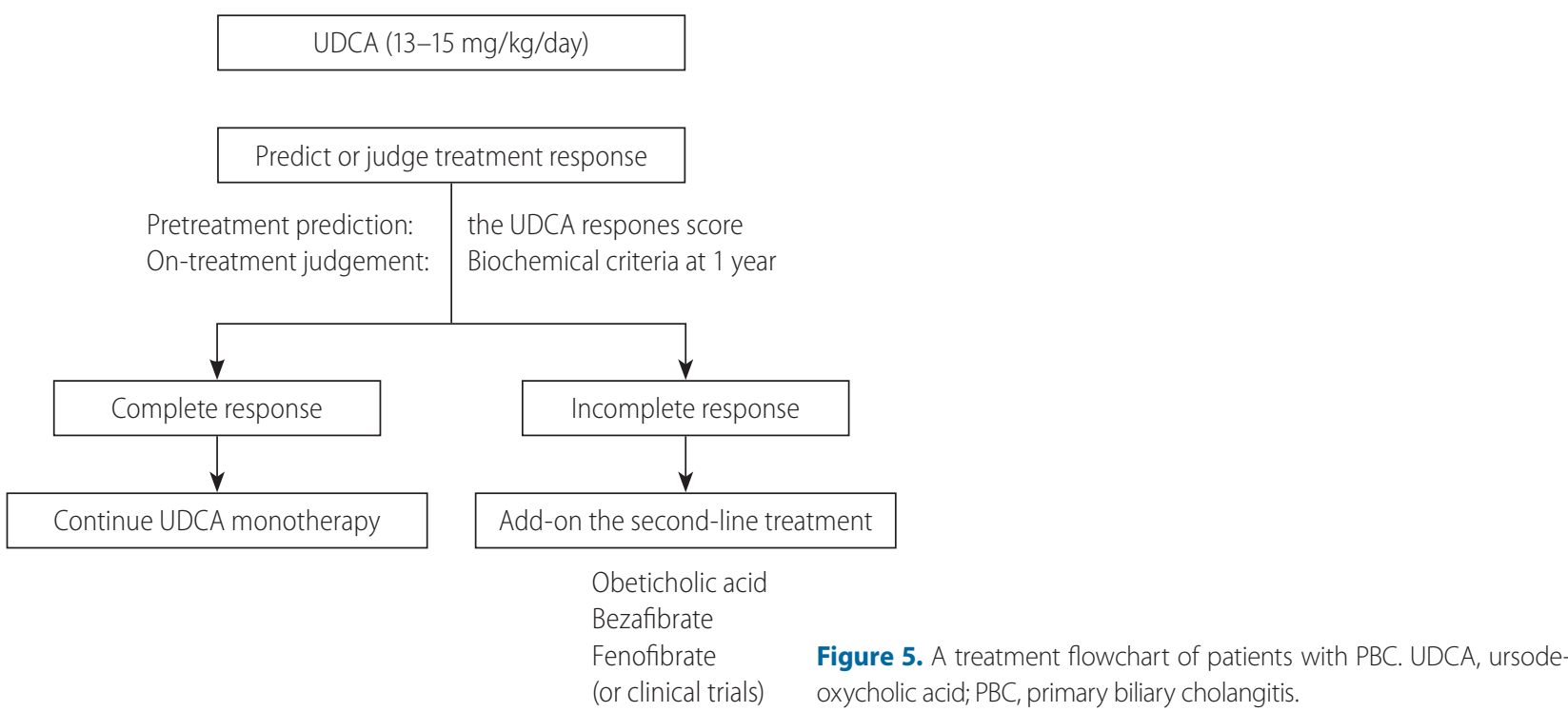




\section{MANAGEMENT OF SYMPTOMS, EXTRAHEPATIC MANIFESTATIONS, AND HEPATOCELLULAR CARCINOMA (HCC)}

Patients with PBC frequently present with numerous symptoms. The most dominant clinical symptoms in the early stage of PBC are fatigue and pruritus, followed by jaundice. Since these symptoms can significantly deteriorate the quality of life of patients with $\mathrm{PBC}$, it is strongly recommended to carefully monitor these symptoms with objective and reproducible measures such as the PBC-40 questionnaire. ${ }^{131}$ In Table 6, symptoms in PBC and corresponding recommended or emerging treatment options are summarized. In addition, along with an improvement in the long-term outcome of patients with PBC, the development of HCC is not a rare event.

\section{Fatigue}

Fatigue is the most common and debilitating symptom in PBC, experienced by approximately $50 \%$ of patients (ranging from $20 \%$ to $80 \%$ depending on each study). ${ }^{132-134}$ Although it is difficult to define the cutoff clearly according to the presence of fatigue, it has been repeatedly shown that fatigue has a great impact on the impairment of the quality of life of patients with PBC. ${ }^{133,135}$ Fatigue is not associated with disease severity and staging, but may be related to age at onset and gender. ${ }^{136}$

The cause of fatigue remains unknown but seems to be complex in origin, probably multifactorial in most patients and associated with depression, autonomic dysfunction, and sleep distur- bance. ${ }^{135}$ Recent studies with magnetic resonance imaging revealed that neuroimaging changes in the brain can be detected even in the early stage of $P B C .{ }^{137}$ Fatigue cannot be treated with UDCA, and a recent systemic review failed to define any established treatment for fatigue in PBC. ${ }^{138}$ Fatigue may be improved by $L T$, but it can also persist in a substantial portion of patients even after LT, making the role of LT as a therapeutic option for severe fatigue questionable..$^{139}$ Modafinil, which is officially approved by the FDA for wakefulness disorders, has been used, but a recent randomized, placebo-controlled clinical trial failed to indicate beneficial effects of this drug in reducing fatigue in patients with $\mathrm{PBC}{ }^{140}$

\section{Pruritus}

Pruritus is another common symptom in PBC, affecting 20 $80 \%$ of patients. Pruritus can occur locally or diffusely, and its presence and severity change throughout the clinical course of PBC. It tends to become more pronounced with the progression of $\mathrm{PBC}$ but can be present even in the very early stage. Pruritus can be highly bothersome and intolerable to patients, such as causing sleep disturbance, and is an important indication for LT. Similar to fatigue, the severity of pruritus is objectively assessable with the PBC-40 questionnaire..$^{131}$ The cause of pruritus remains unknown, although several substances are hypothesized to be related to pruritus in cholestatic liver diseases. ${ }^{1{ }^{11}}$ Most notably, lysophosphatidic acid (LPA) may be a potential candidate for initiating pruritus, ${ }^{142}$ and the activity of serum autotaxin, which converts lysophosphatidylcholine into LPA, and is related to the severity of

Table 6. Symptoms in PBC and corresponding treatment option

\begin{tabular}{lll}
\hline Symptom & \multicolumn{1}{c}{ Treatment } & \multicolumn{1}{c}{ Description } \\
\hline Fatigue & Modafinil & RCT failed to show efficacy \\
\hline Pruritus & Anion-exchange resins (cholestyramine) & The first-line treatment, despite limitations \\
& Rifampicin & The second-line treatment \\
& H-opioid receptor antagonists (naloxone or naltrexone) & The second-line treatment \\
& K-opioid receptor agonist (nalfurafine hydrochloride) & Approved only in Japan \\
& lleal bile acid transporter inhibitor & Linerixibat; efficacy was shown in the Phase 2a; now global \\
& & phase 2b (NCT02966834) \\
& Bezafibrate & Maralixibat; failed to show efficacy \\
Sicca syndrome & Artificial tears and saliva & Now being investigated (NCT02701166) \\
& Pilocarpine or cevimeline & Should be initially used \\
\hline
\end{tabular}

$\mathrm{PBC}$, primary biliary cholangitis; $\mathrm{RCT}$, randomized clinical trial. 
pruritus and responds to therapeutic interventions. ${ }^{143,144}$ Hence, LPA-autotaxin is an important candidate as a therapeutic target, yet clinically unavailable.

Although several lines of treatment options are recommended, severe pruritus is frequently intractable. In daily clinical practice, anion-exchange resins such as cholestyramine, rifampsin, and opiate antagonists are used. ${ }^{145}$ Anion-exchange resins are recommended as the first-line therapy in the American Association for the Study of Liver Diseases and European Association for the Study of the Liver guidelines, despite its limited efficacy. ${ }^{68,146}$ Cholestyramine is prescribed as $4 \mathrm{~g}$ per dose to a maximum of $16 \mathrm{~g} /$ day, and it is important to be administered 1 hour after or 4 hours before other medications (especially UDCA) to avoid inhibiting their absorption. ${ }^{68}$ Rifampicin is a pregnane $X$ receptor agonist that has been used for pruritus at 150-300 mg twice daily. Opiate antangonists interefere with increased endogenous opioid levels in patients with cholestatic pruritus. ${ }^{145}$ While m-opioid receptor antagonists, such as naloxone or naltrexone, have been used, nalfurafine hydrochloride, a selective k-opioid receptor agonist, is currently used in Japan for cholestatic pruritus and exhibits substantial efficacy. ${ }^{147}$ As an emerging novel therapy, an ileal bile acid transporter (IBAT) inhibitor compound (linerixibat) that inhibits reabsorption of bile acids in the ileum effectively decreased pruritus in patients with PBC in a phase 2 a study. ${ }^{148}$ A global phase $2 b$ study (clinical trial ID: NCT02966834) investigating the efficacy of linerixibat is almost complete. A phase 2 trial of another IBAT inhibitor, maralixibat, failed to demonstrate a significant anti-pruritic effect against placebo, presumably because of a significant placebo effect. ${ }^{149}$ As described earlier, bezafibrate is now being investigated in a clinical trial for the treatment of cholestatic pruritus (clinical trial ID: NCT02701166). ${ }^{106}$

\section{Sicca syndrome}

The sicca complex is frequently present in patients with PBC, manifesting as dry eyes and/or dry mouth. External glands, including the lachrymal or salivary glands, are also affected in PBC. A current retrospective study revealed the prevalence of Sjögren's syndrome in up to $56 \%$ of patients with $\mathrm{PBC}, i_{i}^{150}$ however, the sicca complex affects patients with PBC who do not meet the criteria of Sjögren's syndrome. Patients with sicca syndrome may experience many symptoms, including burning, itching, irritated eyes, blepharitis, dysphagia, stomatitis, dental caries, and dry cough, resulting in severe impairment of their quality of life. Early recognition of sicca symptoms and consultations with ophthalmologists or dentists are suggested. Artifical tears and saliva are often helpful, and pilocarpine or cevimeline may alleviate the symptoms in refractory cases.

\section{Osteopenia and osteoporosis}

Osteopenic bone disease, including osteopenia and osteoporosis, is a common disorder in PBC that mainly affects middle-aged women and is associated with an increased risk for fragility fractures. The decrease in bone mineral density found in PBC is multifactorial. Chronic cholestasis leads to malabsorption and deficiency of vitamin D, which is essential for bone metabolism. Other factors associated with bone diseases include age, sex, low body mass index, history of fragility fracture, and advanced stage of PBC. ${ }^{151,152}$ Intervention with bisphosphonates for patients with osteoporosis and those with a history of fragility fracture is safe and improves bone mineral density; ${ }_{i}^{153}$ nonetheless, it remains unclear whether bisphosphonate use is associated with a decrease in fra-

Table 7. Incidence and risk factors for HCC in patients with PBC

\begin{tabular}{|c|c|c|c|c|c|c|}
\hline \multirow{2}{*}{ Country/region } & \multicolumn{2}{|c|}{ Number } & \multicolumn{3}{|c|}{ Incidence* } & \multirow{2}{*}{ Risk factor } \\
\hline & Total & $\mathrm{HCC}$ & All & Male patients & Female patients & \\
\hline Barcelona, Spain $^{158}$ & 389 & 13 & 3.6 & NA & NA & Advanced histological stage \\
\hline Padova, Italy ${ }^{158}$ & 327 & 11 & 3.7 & NA & NA & Advanced histological stage (all), male sex \\
\hline$J^{\prime a p a n}{ }^{171}$ & 2,946 & 71 & 3.6 & 9.5 & 2.9 & $\begin{array}{l}\text { Male sex, advanced histological stage (in } \\
\text { female patients) }\end{array}$ \\
\hline International ${ }^{160}$ & 4,565 & 123 & 3.4 & 6.7 & 2.6 & $\begin{array}{l}\text { Advanced age, male sex, thrombocytopenia } \\
\text { at } 12 \text { months, biochemical non-response }\end{array}$ \\
\hline Beijing, China ${ }^{161}$ & 1,865 & 70 & 6.6 & NA & NA & $\begin{array}{l}\text { Advanced age, male sex, co-existence of } \\
\text { diabetes, History of HBV infection }\end{array}$ \\
\hline
\end{tabular}

$\mathrm{HCC}$, hepatocellular carcinoma; $\mathrm{PBC}$, primary biliary cholangitis; NA, not applicable; HBV, hepatitis B virus.

${ }^{*}$ Cases per 1,000 patient-years. 
gility fractures. Recently, denosumab, a fully human monoclonal antibody against the receptor activator of nuclear factor-kappaB ligand (RANKL), was demonstrated to be effective for treating osteoporosis in patients with $\mathrm{PBC}^{154}$ Since RANK-RANKL signaling might be implicated in the pathogenesis of $\mathrm{PBC}_{1}^{155}$ treatment with denosumab could be used to target both osteoporosis and PBC.

\section{Hyperlipidemia and metabolic syndrome}

Chronic cholestasis is a main feature of PBC, and consequently, hyperlipidemia is common and affects up to $80 \%$ of patients. ${ }^{156}$ Several prospective studies have indicated that an increase in serum lipid levels is not associated with a higher risk for cardiovascular diseases related to atherosclerosis, and treatment for hyperlipidemia per se is not necessary. Notably, these studies were conducted in the 1990s when metabolic syndrome was relatively rare in patients with PBC. A recent study from Italy demonstrated that cardiovascular events developed more frequently in patients with metabolic syndrome, ${ }^{157}$ indicating the importance of treatment intervention for patients with hyperlipidemia if metabolic syndrome exists.

\section{HCC}

$\mathrm{HCC}$ is occasionally encountered in patients with PBC. The reported incidences and risk factors for developing HCC from several large-scale retrospective cohorts are summarized in Table 7. Surprisingly, the incidence rates (cases per 1,000 patient-years) of HCC in all patients with PBC are similar across different regions: 3.6 in Barcelona, Spain; 3.7 in Padova, Italy ${ }_{i}^{158} 3.6$ in a nationwide study in Japan; ${ }^{159}$ and 3.4 in an international cohort. ${ }^{160}$ The incidence rate was exceptionally high (6.6) in a cohort from Beijing, China, ${ }^{161}$ presumably because of the high rate of individuals with previous hepatitis B virus (HBV) infection. A history of HBV infection was identified as an independent risk factor for HCC in this study. The incidence rate was higher in men than in women. In those studies, male sex and advanced histological stage independently contributed to the development of HCC. ${ }^{158-161}$ Treatment response was included among possible risk factors only in the international cohort study, and biochemical non-response at 1 year of UDCA treatment (Paris-I not fulfilled) significantly increased the future risk of HCC (adjusted hazard ratio, 3.44; $95 \% \mathrm{Cl}, 1.65-$ 7.14; $P<0.0001) .{ }^{160}$ Taken together, close monitoring of HCC is strongly recommended for high-risk patients with $\mathrm{PBC}$, such as male patients, those with advanced-stage disease, and non-re- sponders to UDCA. The mean survival of patients who developed HCC was 36 months after diagnosis, and another cohort indicated 5- and 10 -year survival rates of $49.5 \%$ and $31.7 \%$, respectively. ${ }^{162}$

\section{FUTURE PERSPECTIVE}

Although the long-term outcome of PBC has been significantly improved, there remain several unmet needs in PBC. UDCA and other second-line treatments have little efficacy for patients with advanced disease, for whom LT is the only therapeutic option. No "cure" is achieved with current treatment, and patients are required to take medications for life long. A variety of symptoms, including fatigue and pruritus, are very difficult to manage and easily reduce the health-related quality of life.

To overcome these unmet needs in this field, rigorous efforts should be directed at improving our understanding of the environmental etiology and genetic basis of PBC, molecular mechanisms of disease progression, and gender bias to identify critical pathways for therapeutic interventions. Relevant animal models that recapitulate human PBC should be established for preclinical studies with designer drugs guided by this new knowledge. Our goal is achieving the "cure" for PBC.

\section{Acknowledgements}

We deeply appreciate the secretarial assistance of Ms. Kayono Unno. This work was supported by a Health and Labor Sciences Research Grant (research on intractable hepatobiliary disease) issued by the Ministry of Health, Labor, and Welfare of Japan. We would like to thank Editage (www.editage.jp) for English language editing.

\section{Conflicts of Interest}

Atsushi Tanaka received consultant fees from EA Pharma, GlaxoSmithKline, and Gilead Sciences.

\section{REFERENCES}

1. Addison T, Gull W. On a certain affection of the skin-vitiligoideaalpha-plana, B-tuberosa. Guys Hosp Rep 1851;7:265-276.

2. Dauphinee JA, Sinclair JC. Primary biliary cirrhosis. Can Med Assoc J 1949;61:1-6.

3. Beuers U, Gershwin ME, Gish RG, Invernizzi P, Jones DE, Lindor $K$, et al. Changing nomenclature for PBC: from 'cirrhosis' to 'cholangi- 
tis'. Clin Res Hepatol Gastroenterol 2015;39:e57-e59.

4. Beuers U, Gershwin ME, Gish RG, Invernizzi P, Jones DE, Lindor K, et al. Changing nomenclature for PBC: from 'cirrhosis' to 'cholangitis'. Dig Liver Dis 2015;47:924-926.

5. Beuers U, Gershwin ME, Gish RG, Invernizzi P, Jones DE, Lindor K, et al. Changing nomenclature for PBC: from 'cirrhosis' to 'cholangitis'. Am J Gastroenterol 2015;110:1536-1538.

6. Beuers U, Gershwin ME, Gish RG, Invernizzi P, Jones DE, Lindor K, et al. Changing nomenclature for PBC: from 'cirrhosis' to 'cholangitis'. Clin Gastroenterol Hepatol 2015;13:1867-1869.

7. Beuers $U$, Gershwin ME, Gish RG, Invernizzi P, Jones DE, Lindor K, et al. Changing nomenclature for PBC: from 'cirrhosis' to 'cholangitis'. J Hepatol 2015;63:1285-1287.

8. Beuers U, Gershwin ME, Gish RG, Invernizzi P, Jones DE, Lindor K, et al. Changing nomenclature for PBC: from 'cirrhosis' to 'cholangitis'. Gastroenterology 2015;149:1627-1629.

9. Beuers U, Gershwin ME, Gish RG, Invernizzi P, Jones DE, Lindor K, et al. Changing nomenclature for PBC: from 'cirrhosis' to 'cholangitis'. Gut 2015;64:1671-1672.

10. Beuers U, Gershwin ME, Gish RG, Invernizzi P, Jones DE, Lindor $K$, et al. Changing nomenclature for PBC: From 'cirrhosis' to 'cholangitis'. Hepatology 2015;62:1620-1622.

11. Tanaka A, Ma X, Yokosuka O, Weltman M, You H, Amarapurkar $D N$, et al. Autoimmune liver diseases in the Asia-Pacific region: proceedings of APASL symposium on AlH and PBC 2016. Hepatol Int 2016;10:909-915.

12. Cheung KS, Seto WK, Fung J, Lai CL, Yuen MF. Epidemiology and natural history of primary biliary cholangitis in the Chinese: a territory-based study in Hong Kong between 2000 and 2015. Clin Transl Gastroenterol 2017;8:e116.

13. Kim KA, Ki M, Choi HY, Kim BH, Jang ES, Jeong SH. Populationbased epidemiology of primary biliary cirrhosis in South Korea. Aliment Pharmacol Ther 2016;43:154-162.

14. Tanaka A, Mori M, Matsumoto K, Ohira H, Tazuma S, Takikawa H. Increase trend in the prevalence and male-to-female ratio of primary biliary cholangitis, autoimmune hepatitis, and primary sclerosing cholangitis in Japan. Hepatol Res 2019;49:881-889.

15. Jeong SH. Current epidemiology and clinical characteristics of autoimmune liver diseases in South Korea. Clin Mol Hepatol 2018;24: 10-19.

16. Boonstra K, Beuers U, Ponsioen CY. Epidemiology of primary sclerosing cholangitis and primary biliary cirrhosis: a systematic review. J Hepatol 2012;56:1181-1188.

17. French J, van der Mei I, Simpson S Jr, Ng J, Angus P, Lubel J, et al. Increasing prevalence of primary biliary cholangitis in Victoria, Australia. J Gastroenterol Hepatol 2020;35:673-679.

18. Marschall HU, Henriksson I, Lindberg S, Söderdahl F, Thuresson M, Wahlin $S$, et al. Incidence, prevalence, and outcome of primary bili- ary cholangitis in a nationwide Swedish population-based cohort. Sci Rep 2019;9:11525.

19. Lleo A, Jepsen $P$, Morenghi $E$, Carbone M, Moroni L, Battezzati $P M$, et al. Evolving trends in female to male incidence and male mortality of primary biliary cholangitis. Sci Rep 2016;6:25906.

20. Marzioni M, Bassanelli C, Ripellino C, Urbinati D, Alvaro D. Epidemiology of primary biliary cholangitis in Italy: evidence from a realworld database. Dig Liver Dis 2019;51:724-729.

21. Neuberger J, Lombard M, Galbraith R. Primary biliary cirrhosis. Gut 1991;Suppl:S73-S78.

22. Talwalkar J, Lindor K. Primary biliary cirrhosis. Lancet 2003;362:5361.

23. Van de Water J, Gershwin ME, Leung P, Ansari A, Coppel RL. The autoepitope of the $74-\mathrm{kD}$ mitochondrial autoantigen of primary biliary cirrhosis corresponds to the functional site of dihydrolipoamide acetyltransferase. J Exp Med 1988;167:1791-1799.

24. Oertelt S, Rieger R, Selmi C, Invernizzi P, Ansari AA, Coppel RL, et al. A sensitive bead assay for antimitochondrial antibodies: chipping away at AMA-negative primary biliary cirrhosis. Hepatology 2007:45:659-665.

25. Dubel L, Tanaka A, Leung PS, Van de Water J, Coppel R, Roche T, et al. Autoepitope mapping and reactivity of autoantibodies to the dihydrolipoamide dehydrogenase-binding protein (E3BP) and the glycine cleavage proteins in primary biliary cirrhosis. Hepatology 1999;29:1013-1018.

26. Tanaka A, Leung PSC, Gershwin ME. The genetics and epigenetics of primary biliary cholangitis. Clin Liver Dis 2018;22:443-455.

27. Björkland A, Festin R, Mendel-Hartvig I, Nyberg A, Lööf L, Tötterman $\mathrm{TH}$. Blood and liver-infiltrating lymphocytes in primary biliary cirrhosis: increase in activated T and natural killer cells and recruitment of primed memory T cells. Hepatology 1991;13:1106-1111.

28. Krams SM, Van de Water J, Coppel RL, Esquivel C, Roberts J, Ansari $A$, et al. Analysis of hepatic T lymphocyte and immunoglobulin deposits in patients with primary biliary cirrhosis. Hepatology 1990;12:306-313.

29. Imai T, Hieshima K, Haskell C, Baba M, Nagira M, Nishimura M, et al. Identification and molecular characterization of fractalkine receptor CX3CR1, which mediates both leukocyte migration and adhesion. Cell 1997;91:521-530.

30. Isse K, Harada K, Zen Y, Kamihira T, Shimoda S, Harada M, et al. Fractalkine and CX3CR1 are involved in the recruitment of intraepithelial lymphocytes of intrahepatic bile ducts. Hepatology 2005;41:506-516.

31. Shimoda S, Harada K, Niiro H, Taketomi A, Maehara Y, Tsuneyama $\mathrm{K}$, et al. CX3CL1 (fractalkine): a signpost for biliary inflammation in primary biliary cirrhosis. Hepatology 2010;51:567-575.

32. Harada K, Kakuda Y, Nakamura M, Shimoda S, Nakanuma Y. Clinicopathological significance of serum fractalkine in primary biliary 
cirrhosis. Dig Dis Sci 2013;58:3037-3043.

33. Lleo A, Selmi C, Invernizzi P, Podda M, Coppel RL, Mackay IR, et al. Apotopes and the biliary specificity of primary biliary cirrhosis. Hepatology 2009;49:871-879.

34. Lleo A, Bowlus CL, Yang GX, Invernizzi P, Podda M, Van de Water $J$, et al. Biliary apotopes and anti-mitochondrial antibodies activate innate immune responses in primary biliary cirrhosis. Hepatology 2010;52:987-998.

35. Tanaka A, Leung PSC, Gershwin ME. The genetics of primary biliary cholangitis. Curr Opin Gastroenterol 2019;35:93-98.

36. Örnolfsson KT, Olafsson S, Bergmann OM, Gershwin ME, Björnsson ES. Using the Icelandic genealogical database to define the familial risk of primary biliary cholangitis. Hepatology 2018;68:166-171.

37. Cordell HJ, Han Y, Mells GF, Li Y, Hirschfield GM, Greene CS, et al. International genome-wide meta-analysis identifies new primary biliary cirrhosis risk loci and targetable pathogenic pathways. Nat Commun 2015;6:8019.

38. Hirschfield GM, Liu X, Han Y, Gorlov IP, Lu Y, Xu C, et al. Variants at IRF5-TNPO3, 17q12-21 and MMEL1 are associated with primary biliary cirrhosis. Nat Genet 2010;42:655-657.

39. Hirschfield GM, Liu X, Xu C, Lu Y, Xie G, Lu Y, et al. Primary biliary cirrhosis associated with HLA, IL12A, and IL12RB2 variants. N Engl J Med 2009:360:2544-2555.

40. Hirschfield GM, Xie G, Lu E, Sun Y, Juran BD, Chellappa V, et al. Association of primary biliary cirrhosis with variants in the CLEC16A, SOCS1, SPIB and SIAE immunomodulatory genes. Genes Immun 2012;13:328-335.

41. Juran BD, Hirschfield GM, Invernizzi P, Atkinson EJ, Li Y, Xie G, et al. Immunochip analyses identify a novel risk locus for primary biliary cirrhosis at 13q14, multiple independent associations at four established risk loci and epistasis between $1 \mathrm{p} 31$ and $7 \mathrm{q} 32$ risk variants. Hum Mol Genet 2012;21:5209-5221.

42. Kawashima M, Hitomi Y, Aiba Y, Nishida N, Kojima K, Kawai Y, et al. Genome-wide association studies identify PRKCB as a novel genetic susceptibility locus for primary biliary cholangitis in the Japanese population. Hum Mol Genet 2017;26:650-659.

43. Liu JZ, Almarri MA, Gaffney DJ, Mells GF, Jostins L, Cordell HJ, et al. Dense fine-mapping study identifies new susceptibility loci for primary biliary cirrhosis. Nat Genet 2012;44:1137-1141.

44. Liu X, Invernizzi P, Lu Y, Kosoy R, Lu Y, Bianchi I, et al. Genomewide meta-analyses identify three loci associated with primary biliary cirrhosis. Nat Genet 2010;42:658-660.

45. Mells GF, Floyd JA, Morley KI, Cordell HJ, Franklin CS, Shin SY, et al. Genome-wide association study identifies 12 new susceptibility loci for primary biliary cirrhosis. Nat Genet 2011;43:329-332.

46. Nakamura M, Nishida N, Kawashima M, Aiba Y, Tanaka A, Yasunami $M$, et al. Genome-wide association study identifies TNFSF15 and POU2AF1 as susceptibility loci for primary biliary cirrhosis in the Japanese population. Am J Hum Genet 2012;91:721-728.

47. Qiu F, Tang R, Zuo X, Shi X, Wei Y, Zheng X, et al. A genome-wide association study identifies six novel risk loci for primary biliary cholangitis. Nat Commun 2017;8:14828.

48. Dong M, Li J, Tang R, Zhu P, Qiu F, Wang C, et al. Multiple genetic variants associated with primary biliary cirrhosis in a Han Chinese population. Clin Rev Allergy Immunol 2015;48:316-321.

49. Burroughs AK, Rosenstein IJ, Epstein O, Hamilton-Miller JM, Brumfitt W, Sherlock S. Bacteriuria and primary biliary cirrhosis. Gut 1984;25:133-137.

50. Corpechot C, Chrétien Y, Chazouillères O, Poupon R. Demographic, lifestyle, medical and familial factors associated with primary biliary cirrhosis. J Hepatol 2010;53:162-169.

51. Gershwin ME, Selmi C, Worman HJ, Gold EB, Watnik M, Utts J, et al. Risk factors and comorbidities in primary biliary cirrhosis: a controlled interview-based study of 1032 patients. Hepatology 2005:42:1194-1202.

52. Howel D, Fischbacher CM, Bhopal RS, Gray J, Metcalf JV, James OF. An exploratory population-based case-control study of primary biliary cirrhosis. Hepatology 2000;31:1055-1060.

53. Ala A, Stanca CM, Bu-Ghanim M, Ahmado I, Branch AD, Schiano TD, et al. Increased prevalence of primary biliary cirrhosis near superfund toxic waste sites. Hepatology 2006;43:525-531.

54. Amano K, Leung PS, Rieger R, Quan C, Wang X, Marik J, et al. Chemical xenobiotics and mitochondrial autoantigens in primary biliary cirrhosis: identification of antibodies against a common environmental, cosmetic, and food additive, 2-octynoic acid. J Immunol 2005;174:5874-5883.

55. McNally RJ, James PW, Ducker S, Norman PD, James OF. No rise in incidence but geographical heterogeneity in the occurrence of primary biliary cirrhosis in North East England. Am J Epidemiol 2014;179:492-498.

56. Prince MI, Chetwynd A, Diggle P, Jarner M, Metcalf JV, James OF. The geographical distribution of primary biliary cirrhosis in a welldefined cohort. Hepatology 2001;34:1083-1088.

57. Rieger R, Leung PS, Jeddeloh MR, Kurth MJ, Nantz MH, Lam KS, et al. Identification of 2-nonynoic acid, a cosmetic component, as a potential trigger of primary biliary cirrhosis. J Autoimmun 2006;27:7-16.

58. Tang R, Wei Y, Li Y, Chen W, Chen H, Wang Q, et al. Gut microbial profile is altered in primary biliary cholangitis and partially restored after UDCA therapy. Gut 2018;67:534-541.

59. Ma HD, Zhao ZB, Ma WT, Liu QZ, Gao CY, Li L, et al. Gut microbiota translocation promotes autoimmune cholangitis. J Autoimmun 2018;95:47-57.

60. Ryan PM, Stanton C, Caplice NM. Bile acids at the cross-roads of gut microbiome-host cardiometabolic interactions. Diabetol Metab Syndr 2017;9:102. 
61. Staley C, Weingarden AR, Khoruts A, Sadowsky MJ. Interaction of gut microbiota with bile acid metabolism and its influence on disease states. Appl Microbiol Biotechnol 2017;101:47-64.

62. Hofmann AF, Hagey LR, Krasowski MD. Bile salts of vertebrates: structural variation and possible evolutionary significance. J Lipid Res 2010;51:226-246.

63. Chen ML, Takeda K, Sundrud MS. Emerging roles of bile acids in mucosal immunity and inflammation. Mucosal Immunol 2019;12: 851-861.

64. Yang $H$, Duan Z. Bile acids and the potential role in primary biliary cirrhosis. Digestion 2016;94:145-153.

65. Li Y, Tang R, Leung PSC, Gershwin ME, Ma X. Bile acids and intestinal microbiota in autoimmune cholestatic liver diseases. Autoimmun Rev 2017;16:885-896.

66. Melbye P, Olsson A, Hansen TH, Søndergaard HB, Bang Oturai A. Short-chain fatty acids and gut microbiota in multiple sclerosis. Acta Neurol Scand 2019;139:208-219.

67. Jones-Hall YL, Nakatsu CH. The intersection of TNF, IBD and the microbiome. Gut Microbes 2016;7:58-62.

68. Lindor KD, Bowlus CL, Boyer J, Levy C, Mayo M. Primary biliary cholangitis: 2018 practice guidance from the American Association for the Study of Liver Diseases. Hepatology 2019;69:394-419.

69. Working Subgroup for Clinical Practice Guidelines for Primary Biliary Cirrhosis. Guidelines for the management of primary biliary cirrhosis: the intractable hepatobiliary disease study group supported by the Ministry of Health, Labour and Welfare of Japan. Hepatol Res 2014;44 Suppl 51:71-90.

70. Murillo Perez CF, Hirschfield GM, Corpechot C, Floreani A, Mayo MJ, van der Meer $A$, et al. Fibrosis stage is an independent predictor of outcome in primary biliary cholangitis despite biochemical treatment response. Aliment Pharmacol Ther 2019;50:1127-1136.

71. Joshi S, Cauch-Dudek K, Heathcote EJ, Lindor K, Jorgensen R, Klein R. Antimitochondrial antibody profiles: are they valid prognostic indicators in primary biliary cirrhosis? Am J Gastroenterol 2002;97:999-1002.

72. Mattalia A, Quaranta S, Leung PS, Bauducci M, Van de Water J, Calvo $\mathrm{PL}$, et al. Characterization of antimitochondrial antibodies in health adults. Hepatology 1998;27:656-661.

73. Shibata M, Onozuka Y, Morizane T, Koizumi H, Kawaguchi N, Mi-

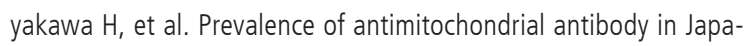
nese corporate workers in Kanagawa prefecture. J Gastroenterol 2004;39:255-259.

74. Dahlqvist G, Gaouar F, Carrat F, Meurisse S, Chazouillères O, Poupon $R$, et al. Large-scale characterization study of patients with antimitochondrial antibodies but nonestablished primary biliary cholangitis. Hepatology 2017;65:152-163.

75. Sun C, Xiao X, Yan L, Sheng L, Wang Q, Jiang P, et al. Histologically proven AMA positive primary biliary cholangitis but normal serum alkaline phosphatase: is alkaline phosphatase truly a surrogate marker? J Autoimmun 2019;99:33-38

76. Liu H, Norman GL, Shums Z, Worman HJ, Krawitt EL, Bizzaro N, et al. PBC screen: an IgG/IgA dual isotype ELISA detecting multiple mitochondrial and nuclear autoantibodies specific for primary biliary cirrhosis. J Autoimmun 2010;35:436-442.

77. Shimoda S, Nakamura M, Ishibashi H, Kawano A, Kamihira T, Sakamoto $N$, et al. Molecular mimicry of mitochondrial and nuclear autoantigens in primary biliary cirrhosis. Gastroenterology 2003;124:1915-1925.

78. Nakamura $\mathrm{M}$, Kondo $\mathrm{H}$, Mori $\mathrm{T}$, Komori $\mathrm{A}$, Matsuyama $\mathrm{M}$, Ito $\mathrm{M}$, et al. Anti-gp210 and anti-centromere antibodies are different risk factors for the progression of primary biliary cirrhosis. Hepatology 2007:45:118-127.

79. Scheuer P. Primary biliary cirrhosis. Proc R Soc Med 1967;60:12571260.

80. Ludwig J, Dickson ER, McDonald GS. Staging of chronic nonsuppurative destructive cholangitis (syndrome of primary biliary cirrhosis). Virchows Arch A Pathol Anat Histol 1978;379:103-112.

81. Nakanuma Y, Zen Y, Harada K, Sasaki M, Nonomura A, Uehara T, et al. Application of a new histological staging and grading system for primary biliary cirrhosis to liver biopsy specimens: interobserver agreement. Pathol Int 2010;60:167-174.

82. Harada K, Hsu M, Ikeda H, Zeniya M, Nakanuma Y. Application and validation of a new histologic staging and grading system for primary biliary cirrhosis. J Clin Gastroenterol 2013;47:174-181.

83. Poupon R, Chrétien Y, Poupon RE, Ballet F, Calmus Y, Darnis F. Is ursodeoxycholic acid an effective treatment for primary biliary cirrhosis? Lancet 1987;1:834-836.

84. Lindor KD, Gershwin ME, Poupon R, Kaplan M, Bergasa NV, Heathcote EJ, et al. Primary biliary cirrhosis. Hepatology 2009;50:291308.

85. Harms MH, van Buuren HR, Corpechot C, Thorburn D, Janssen $H L A$, Lindor KD, et al. Ursodeoxycholic acid therapy and liver transplant-free survival in patients with primary biliary cholangitis. J Hepatol 2019;71:357-365.

86. Azemoto N, Abe M, Murata Y, Hiasa Y, Hamada M, Matsuura B, et al. Early biochemical response to ursodeoxycholic acid predicts symptom development in patients with asymptomatic primary biliary cirrhosis. J Gastroenterol 2009;44:630-634.

87. Carbone M, Sharp SJ, Flack S, Paximadas D, Spiess K, Adgey C, et al. The UK-PBC risk scores: derivation and validation of a scoring system for long-term prediction of end-stage liver disease in primary biliary cholangitis. Hepatology 2016;63:930-950.

88. Corpechot C, Abenavoli L, Rabahi N, Chrétien Y, Andréani T, Johanet $C$, et al. Biochemical response to ursodeoxycholic acid and long-term prognosis in primary biliary cirrhosis. Hepatology 2008;48:871-877 
89. Corpechot C, Chazouillères O, Poupon R. Early primary biliary cirrhosis: biochemical response to treatment and prediction of longterm outcome. J Hepatol 2011;55:1361-1367.

90. Kuiper EM, Hansen BE, de Vries RA, den Ouden-Muller JW, van Ditzhuijsen TJ, Haagsma EB, et al. Improved prognosis of patients with primary biliary cirrhosis that have a biochemical response to ursodeoxycholic acid. Gastroenterology 2009;136:1281-1287.

91. Kumagi T, Guindi M, Fischer SE, Arenovich T, Abdalian R, Coltescu $C$, et al. Baseline ductopenia and treatment response predict longterm histological progression in primary biliary cirrhosis. Am J Gastroenterol 2010;105:2186-2194.

92. Lammers WJ, Hirschfield GM, Corpechot C, Nevens F, Lindor KD, Janssen $\mathrm{HL}$, et al. Development and validation of a scoring system to predict outcomes of patients with primary biliary cirrhosis receiving ursodeoxycholic acid therapy. Gastroenterology 2015;149:18041812.e4.

93. Lammers WJ, van Buuren HR, Hirschfield GM, Janssen HL, Invernizzi $P$, Mason $A L$, et al. Levels of alkaline phosphatase and bilirubin are surrogate end points of outcomes of patients with primary biliary cirrhosis: an international follow-up study. Gastroenterology 2014;147:1338-1349.e5; quiz e15.

94. Momah N, Silveira MG, Jorgensen R, Sinakos E, Lindor KD. Optimizing biochemical markers as endpoints for clinical trials in primary biliary cirrhosis. Liver Int 2012;32:790-795.

95. Parés A, Caballería L, Rodés J. Excellent long-term survival in patients with primary biliary cirrhosis and biochemical response to ursodeoxycholic acid. Gastroenterology 2006;130:715-720.

96. Carbone M, Nardi A, Flack S, Carpino G, Varvaropoulou N, Gavrila $C$, et al. Pretreatment prediction of response to ursodeoxycholic acid in primary biliary cholangitis: development and validation of the UDCA response score. Lancet Gastroenterol Hepatol 2018;3:626-634.

97. Yagi $M$, Matsumoto $K$, Komori A, Abe M, Hashimoto $N$, Inao $M$, et al. A validation study of the ursodeoxycholic acid response score in Japanese patients with primary biliary cholangitis. Liver Int 2020;40:1926-1933.

98. Nevens F, Andreone P, Mazzella G, Strasser SI, Bowlus C, Invernizzi $P$, et al. A placebo-controlled trial of obeticholic acid in primary biliary cholangitis. N Engl J Med 2016;375:631-643.

99. Samur S, Klebanoff M, Banken R, Pratt DS, Chapman R, Ollendorf $D A$, et al. Long-term clinical impact and cost-effectiveness of obeticholic acid for the treatment of primary biliary cholangitis. Hepatology 2017;65:920-928.

100. Trauner M, Nevens F, Shiffman ML, Drenth JPH, Bowlus CL, Vargas $V$, et al. Long-term efficacy and safety of obeticholic acid for patients with primary biliary cholangitis: 3-year results of an international open-label extension study. Lancet Gastroenterol Hepatol 2019:4:445-453.
101. Bowlus $C L$, Pockros PJ, Kremer AE, Parés $A$, Forman $L M$, Drenth $\mathrm{JPH}$, et al. Long-term obeticholic acid therapy improves histological endpoints in patients with primary biliary cholangitis. Clin Gastroenterol Hepatol 2020;18:1170-1178.e6.

102. Honda A, Ikegami T, Nakamuta M, Miyazaki T, Iwamoto J, Hirayama $T$, et al. Anticholestatic effects of bezafibrate in patients with primary biliary cirrhosis treated with ursodeoxycholic acid. Hepatology 2013;57:1931-1941.

103. Iwasaki S, Tsuda K, Ueta H, Aono R, Ono M, Saibara T, et al. Bezafibrate may have a beneficial effect in pre-cirrhotic primary biliary cirrhosis. Hepatology Research 1999;16:12-18.

104. Corpechot C, Chazouillères O, Rousseau A, Le Gruyer A, Habersetzer $F$, Mathurin $P$, et al. A placebo-controlled trial of bezafibrate in primary biliary cholangitis. N Engl J Med 2018;378:2171-2181.

105. Honda A, Tanaka A, Kaneko T, Komori A, Abe M, Inao M, et al. Bezafibrate improves GLOBE and UK-PBC scores and long-term outcomes in patients with primary biliary cholangitis. Hepatology 2019;70:2035-2046.

106. Bolier R, de Vries ES, Parés A, Helder J, Kemper EM, Zwinderman $\mathrm{K}$, et al. Fibrates for the treatment of cholestatic itch (FITCH): study protocol for a randomized controlled trial. Trials 2017;18:230.

107. Cheung AC, Lapointe-Shaw L, Kowgier M, Meza-Cardona J, Hirschfield GM, Janssen HL, et al. Combined ursodeoxycholic acid (UDCA) and fenofibrate in primary biliary cholangitis patients with incomplete UDCA response may improve outcomes. Aliment Pharmacol Ther 2016;43:283-293.

108. Dohmen K, Mizuta T, Nakamuta M, Shimohashi N, Ishibashi $H$, Yamamoto K. Fenofibrate for patients with asymptomatic primary biliary cirrhosis. World J Gastroenterol 2004;10:894-898.

109. Hegade VS, Khanna A, Walker LJ, Wong LL, Dyson JK, Jones DEJ. Long-term fenofibrate treatment in primary biliary cholangitis improves biochemistry but not the UK-PBC risk score. Dig Dis Sci 2016;61:3037-3044.

110. Harms MH, Janssen QP, Adam R, Duvoux C, Mirza D, Hidalgo E, et al. Trends in liver transplantation for primary biliary cholangitis in Europe over the past three decades. Aliment Pharmacol Ther 2019:49:285-295.

111. Adam R, Karam V, Delvart V, O'Grady J, Mirza D, Klempnauer J, et al. Evolution of indications and results of liver transplantation in Europe. A report from the European Liver Transplant Registry (ELTR). J Hepatol 2012;57:675-688.

112. Singal AK, Guturu P, Hmoud B, Kuo YF, Salameh H, Wiesner RH. Evolving frequency and outcomes of liver transplantation based on etiology of liver disease. Transplantation 2013;95:755-760.

113. The Japanese Liver Transplantation Society. Liver transplantation in Japan. -Registry by the Japanese Liver Transplantation Society-. Jpn J Transplant 2015;52:134-147.

114. Bhanji RA, Mason AL, Girgis S, Montano-Loza AJ. Liver transplan- 
tation for overlap syndromes of autoimmune liver diseases. Liver Int 2013;33:210-219.

115. Carbone M, Mells GF, Alexander GJ, Westbrook RH, Heneghan MA, Sandford RN, et al. Calcineurin inhibitors and the IL12A locus influence risk of recurrent primary biliary cirrhosis after liver transplantation. Am J Transplant 2013;13:1110-1111.

116. Charatcharoenwitthaya P, Pimentel S, Talwalkar JA, Enders FT, Lindor KD, Krom RA, et al. Long-term survival and impact of ursodeoxycholic acid treatment for recurrent primary biliary cirrhosis after liver transplantation. Liver Transpl 2007;13:1236-1245.

117. Egawa H, Sakisaka S, Teramukai S, Sakabayashi S, Yamamoto M, Umeshita $K$, et al. Long-term outcomes of living-donor liver transplantation for primary biliary cirrhosis: a Japanese multicenter study. Am J Transplant 2016;16:1248-1257.

118. Guy JE, Qian P, Lowell JA, Peters MG. Recurrent primary biliary cirrhosis: peritransplant factors and ursodeoxycholic acid treatment post-liver transplant. Liver Transpl 2005;11:1252-1257.

119. Hytiroglou P, Gutierrez JA, Freni M, Odin JA, Stanca CM, Merati $S$, et al. Recurrence of primary biliary cirrhosis and development of autoimmune hepatitis after liver transplant: a blind histologic study. Hepatol Res 2009;39:577-584.

120. Jacob DA, Neumann UP, Bahra M, Klupp J, Puhl G, Neuhaus R, et al. Long-term follow-up after recurrence of primary biliary cirrhosis after liver transplantation in 100 patients. Clin Transplant 2006:20:211-220.

121. Khettry U, Anand N, Faul PN, Lewis WD, Pomfret EA, Pomposelli J, et al. Liver transplantation for primary biliary cirrhosis: a long-term pathologic study. Liver Transpl 2003;9:87-96.

122. Kogiso T, Egawa H, Teramukai S, Taniai M, Hashimoto E, Tokushige $\mathrm{K}$, et al. Risk factors for recurrence of primary biliary cholangitis after liver transplantation in female patients: a Japanese multicenter retrospective study. Hepatol Commun 2017;1:394-405.

123. Liermann Garcia RF, Evangelista Garcia C, McMaster P, Neuberger J. Transplantation for primary biliary cirrhosis: retrospective analysis of 400 patients in a single center. Hepatology 2001;33:22-27.

124. Manousou P, Arvaniti V, Tsochatzis E, Isgro G, Jones K, Shirling G, et al. Primary biliary cirrhosis after liver transplantation: influence of immunosuppression and human leukocyte antigen locus disparity. Liver Transpl 2010;16:64-73.

125. Montano-Loza AJ, Hansen BE, Corpechot C, Roccarina D, Thorburn $D$, Trivedi $P$, et al. Factors associated with recurrence of primary biliary cholangitis after liver transplantation and effects on graft and patient survival. Gastroenterology 2019;156:96-107.e1.

126. Montano-Loza AJ, Wasilenko S, Bintner J, Mason AL. Cyclosporine A protects against primary biliary cirrhosis recurrence after liver transplantation. Am J Transplant 2010;10:852-858.

127. Neuberger J, Gunson B, Hubscher S, Nightingale P. Immunosuppression affects the rate of recurrent primary biliary cirrhosis after liver transplantation. Liver Transpl 2004;10:488-491.

128. Sanchez EQ, Levy MF, Goldstein RM, Fasola CG, Tillery GW, Netto GJ, et al. The changing clinical presentation of recurrent primary biliary cirrhosis after liver transplantation. Transplantation 2003;76:1583-1588.

129. Sylvestre PB, Batts KP, Burgart LJ, Poterucha JJ, Wiesner RH. Recurrence of primary biliary cirrhosis after liver transplantation: histologic estimate of incidence and natural history. Liver Transpl 2003;9:1086-1093.

130. Bosch A, Dumortier J, Maucort-Boulch D, Scoazec JY, Wendum D, Conti $F$, et al. Preventive administration of UDCA after liver transplantation for primary biliary cirrhosis is associated with a lower risk of disease recurrence. J Hepatol 2015;63:1449-1458.

131. Jacoby A, Rannard A, Buck D, Bhala N, Newton JL, James OF, et al. Development, validation, and evaluation of the PBC-40, a disease specific health related quality of life measure for primary biliary cirrhosis. Gut 2005;54:1622-1629.

132. Huet PM, Deslauriers J, Tran A, Faucher C, Charbonneau J. Impact of fatigue on the quality of life of patients with primary biliary cirrhosis. Am J Gastroenterol 2000;95:760-767.

133. Mells GF, Pells G, Newton JL, Bathgate AJ, Burroughs AK, Heneghan MA, et al. Impact of primary biliary cirrhosis on perceived quality of life: the UK-PBC national study. Hepatology 2013:58:273-283

134. Prince M, Chetwynd A, Newman W, Metcalf JV, James OF. Survival and symptom progression in a geographically based cohort of patients with primary biliary cirrhosis: follow-up for up to 28 years. Gastroenterology 2002;123:1044-1051.

135. Jopson L, Jones DE. Fatigue in primary biliary cirrhosis: prevalence, pathogenesis and management. Dig Dis 2015;33 Suppl 2:109-114.

136. Carbone M, Mells GF, Pells G, Dawwas MF, Newton JL, Heneghan $M A$, et al. Sex and age are determinants of the clinical phenotype of primary biliary cirrhosis and response to ursodeoxycholic acid. Gastroenterology 2013;144:560-569.e7; quiz e13-e14.

137. Grover VP, Southern L, Dyson JK, Kim JU, Crossey MM, WylezinskaArridge $\mathrm{M}$, et al. Early primary biliary cholangitis is characterised by brain abnormalities on cerebral magnetic resonance imaging. Aliment Pharmacol Ther 2016;44:936-945.

138. Lee JY, Danford CJ, Trivedi HD, Tapper EB, Patwardhan VR, Bonder A. Treatment of fatigue in primary biliary cholangitis: a systematic review and meta-analysis. Dig Dis Sci 2019;64:2338-2350.

139. Carbone M, Bufton S, Monaco A, Griffiths L, Jones DE, Neuberger JM. The effect of liver transplantation on fatigue in patients with primary biliary cirrhosis: a prospective study. J Hepatol 2013:59:490-494.

140. Silveira MG, Gossard AA, Stahler AC, Jorgensen RA, Petz JL, Ali $\mathrm{AH}$, et al. A randomized, placebo-controlled clinical trial of efficacy and safety: modafinil in the treatment of fatigue in patients with 
primary biliary cirrhosis. Am J Ther 2017;24:e167-e176.

141. Beuers U, Kremer AE, Bolier R, Elferink RP. Pruritus in cholestasis: facts and fiction. Hepatology 2014;60:399-407.

142. Kremer AE, Martens JJ, Kulik W, Ruëff F, Kuiper EM, van Buuren $H R$, et al. Lysophosphatidic acid is a potential mediator of cholestatic pruritus. Gastroenterology 2010;139:1008-1018.e1.

143. Kremer AE, Martens J, Kulik W, Williamson C, Moolenaar WH, Kondrackiene J, et al. Autotaxin but not bile salts correlate with itch intensity in cholestasis. J Hepatol 2010;52:S1.

144. Kremer AE, van Dijk R, Leckie P, Schaap FG, Kuiper EM, Mettang $T$, et al. Serum autotaxin is increased in pruritus of cholestasis, but not of other origin, and responds to therapeutic interventions. Hepatology 2012;56:1391-1400.

145. Tandon P, Rowe BH, Vandermeer B, Bain VG. The efficacy and safety of bile acid binding agents, opioid antagonists, or rifampin in the treatment of cholestasis-associated pruritus. Am J Gastroenterol 2007;102:1528-1536.

146. European Association for the Study of the Liver. EASL clinical practice guidelines: the diagnosis and management of patients with primary biliary cholangitis. J Hepatol 2017;67:145-172.

147. Yagi M, Tanaka A, Namisaki T, Takahashi A, Abe M, Honda A, et al. Is patient-reported outcome improved by nalfurafine hydrochloride in patients with primary biliary cholangitis and refractory pruritus? A post-marketing, single-arm, prospective study. J Gastroenterol 2018;53:1151-1158.

148. Hegade VS, Kendrick SF, Dobbins RL, Miller SR, Thompson D, Richards $D$, et al. Effect of ileal bile acid transporter inhibitor GSK2330672 on pruritus in primary biliary cholangitis: a doubleblind, randomised, placebo-controlled, crossover, phase 2a study. Lancet 2017;389:1114-1123.

149. Mayo MJ, Pockros PJ, Jones D, Bowlus CL, Levy C, Patanwala I, et al. A randomized, controlled, phase 2 study of maralixibat in the treatment of itching associated with primary biliary cholangitis. Hepatol Commun 2019;3:365-381.

150. Floreani A, Franceschet I, Cazzagon N, Spinazzè A, Buja A, Furlan P, et al. Extrahepatic autoimmune conditions associated with primary biliary cirrhosis. Clin Rev Allergy Immunol 2015;48:192-197.

151. Guañabens N, Cerdá D, Monegal A, Pons F, Caballería L, Peris P, et al. Low bone mass and severity of cholestasis affect fracture risk in patients with primary biliary cirrhosis. Gastroenterology 2010;138:2348-2356.

152. Guañabens N, Parés A, Ros I, Caballería L, Pons F, Vidal S, et al. Severity of cholestasis and advanced histological stage but not menopausal status are the major risk factors for osteoporosis in primary biliary cirrhosis. J Hepatol 2005;42:573-577.

153. Guañabens N, Monegal A, Cerdá D, Muxí Á, Gifre L, Peris P, et al. Randomized trial comparing monthly ibandronate and weekly alendronate for osteoporosis in patients with primary biliary cirrhosis.
Hepatology 2013;58:2070-2078.

154. Arase Y, Tsuruya K, Hirose S, Ogiwara N, Yokota M, Anzai K, et al. Efficacy and safety of 3-year denosumab therapy for osteoporosis in patients with autoimmune liver diseases. Hepatology 2020;71:757-759.

155. Lleo A, Bian Z, Zhang H, Miao Q, Yang F, Peng Y, et al. Quantitation of the rank-rankl axis in primary biliary cholangitis. PLoS One 2016;11:e0159612.

156. Sorokin A, Brown JL, Thompson PD. Primary biliary cirrhosis, hyperlipidemia, and atherosclerotic risk: a systematic review. Atherosclerosis 2007:194:293-299.

157. Floreani A, Cazzagon N, Franceschet I, Canesso F, Salmaso L, Baldo $\mathrm{V}$. Metabolic syndrome associated with primary biliary cirrhosis. J Clin Gastroenterol 2015;49:57-60.

158. Cavazza A, Caballería L, Floreani A, Farinati F, Bruguera M, Caroli $D$, et al. Incidence, risk factors, and survival of hepatocellular carcinoma in primary biliary cirrhosis: comparative analysis from two centers. Hepatology 2009;50:1162-1168.

159. Harada K, Hirohara J, Ueno Y, Nakano T, Kakuda Y, Tsubouchi H, et al. Incidence of and risk factors for hepatocellular carcinoma in primary biliary cirrhosis: national data from Japan. Hepatology 2013;57:1942-1949.

160. Trivedi PJ, Lammers WJ, van Buuren HR, Parés A, Floreani A, Janssen $\mathrm{HL}$, et al. Stratification of hepatocellular carcinoma risk in primary biliary cirrhosis: a multicentre international study. Gut 2016;65:321-329.

161. Rong G, Wang H, Bowlus CL, Wang C, Lu Y, Zeng Z, et al. Incidence and risk factors for hepatocellular carcinoma in primary biliary cirrhosis. Clin Rev Allergy Immunol 2015;48:132-141.

162. Imam MH, Silveira $M G$, Sinakos $E$, Gossard $A A$, Jorgensen $R$, Keach $J$, et al. Long-term outcomes of patients with primary biliary cirrhosis and hepatocellular carcinoma. Clin Gastroenterol Hepatol 2012;10:182-185.

163. Ellinghaus D, Folseraas T, Holm K, Ellinghaus E, Melum E, Balschun $T$, et al. Genome-wide association analysis in primary sclerosing cholangitis and ulcerative colitis identifies risk loci at GPR35 and TCF4. Hepatology 2013;58:1074-1083.

164. Ellinghaus D, Jostins L, Spain SL, Cortes A, Bethune J, Han B, et al. Analysis of five chronic inflammatory diseases identifies 27 new associations and highlights disease-specific patterns at shared loci. Nat Genet 2016;48:510-518.

165. Folseraas T, Melum E, Rausch P, Juran BD, Ellinghaus E, Shiryaev $A$, et al. Extended analysis of a genome-wide association study in primary sclerosing cholangitis detects multiple novel risk loci. J Hepatol 2012;57:366-375.

166. Ji SG, Juran BD, Mucha S, Folseraas T, Jostins L, Melum E, et al. Genome-wide association study of primary sclerosing cholangitis identifies new risk loci and quantifies the genetic relationship with 
inflammatory bowel disease. Nat Genet 2017;49:269-273.

167. Karlsen TH, Franke A, Melum E, Kaser A, Hov JR, Balschun T, et al. Genome-wide association analysis in primary sclerosing cholangitis. Gastroenterology 2010;138:1102-1111.

168. Liu JZ, Hov JR, Folseraas T, Ellinghaus E, Rushbrook SM, Doncheva NT, et al. Dense genotyping of immune-related disease regions identifies nine new risk loci for primary sclerosing cholangitis. Nat Genet 2013;45:670-675

169. Melum E, Franke A, Schramm C, Weismüller TJ, Gotthardt DN,
Offner FA, et al. Genome-wide association analysis in primary sclerosing cholangitis identifies two non-HLA susceptibility loci. Nat Genet 2011;43:17-19.

170. Srivastava B, Mells GF, Cordell HJ, Muriithi A, Brown M, Ellinghaus $E$, et al. Fine mapping and replication of genetic risk loci in primary sclerosing cholangitis. Scand J Gastroenterol 2012;47:820-826.

171. Harada K, Nakanuma Y. Prevalence and risk factors of hepatocellular carcinoma in Japanese patients with primary biliary cirrhosis. Hepatol Res 2014;44:133-140. 